Research Articles: Cellular/Molecular

\title{
DSCAM deficiency leads to premature spine maturation and autism-like behaviors
}

https://doi.org/10.1523/JNEUROSCI.1003-21.2021

Cite as: J. Neurosci 2021; 10.1523/JNEUROSCI.1003-21.2021

Received: 12 May 2021

Revised: 12 November 2021

Accepted: 19 November 2021

This Early Release article has been peer-reviewed and accepted, but has not been through the composition and copyediting processes. The final version may differ slightly in style or formatting and will contain links to any extended data.

Alerts: Sign up at www.jneurosci.org/alerts to receive customized email alerts when the fully formatted version of this article is published.

Copyright $@ 2021$ Chen et al.

This is an open-access article distributed under the terms of the Creative Commons Attribution 4.0 International license, which permits unrestricted use, distribution and reproduction in any medium provided that the original work is properly attributed. 


\section{behaviors}

3

4 Abbreviated title: Spine and behavioral deficits by loss of DSCAM

5

6 Peng Chen ${ }^{1,2,6}$, Ziyang Liü ${ }^{1,2,6}$, Qian Zhang ${ }^{3}$, Dong Lin ${ }^{1,2}$, Lu Song ${ }^{4}$, Jianghong Liu ${ }^{4}$,

7 Hui-Feng Jiao ${ }^{3}$, Xinsheng Lai $^{1,2}$, Suqi Zou ${ }^{1,2}$, Shunqi Wang ${ }^{1,2}$, Tian Zhou ${ }^{3}$, Bao-Ming

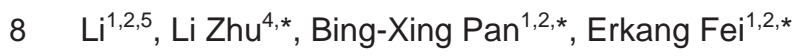

9

${ }^{1}$ School of Life Sciences, Nanchang University, Nanchang, 330031, China.

${ }^{2}$ Institute of Life Science, Nanchang University, Nanchang, 330031, China.

${ }^{3}$ School of Basic Medical Sciences, Nanchang University, Nanchang, 330031, China.

${ }^{4}$ State Key Laboratory of Brain and Cognitive Science, Institute of Biophysics,

Chinese Academy of Science, Beijing, 100101, China

${ }^{5}$ School of Education, Hangzhou Normal University, Hangzhou, 311121, China

${ }^{6}$ These authors contributed equally to this work.

*Correspondence: fek@ncu.edu.cn (EF); panbingxing@ncu.edu.cn (B-XP);

zhuli@ibp.ac.cn (LZ)

Number of pages: 59

Number of figures: 11

Number of words: Abstract, 164 words; Introduction, 659 wor'ds; Discussion, 1135 
Conflict of interest:

The authors declare no conflict of interest.

28

\section{Acknowledgments:}

30 5

We thank Dr. Jane Y Wu (Institute of Biophysics, Chinese Academy of Science) for providing the DSCAM f/f mice, Dr. Yu-Qiang Ding (Fudan University) for providing the NEX-Cre mice, Dr. Peng Zhang (Case Western Reserve University) for providing technical assistance, Dr. Yaoyao Bian (Nanjing University of Chinese Medicine) for their suggestions on our manuscript. This work was supported by grants from the National Natural Science Foundation of China (Grant Nos. 31771142 and 81460215 [to EF], 82125010 and 81930032 [to B-XP], 31860268 [to TZ], 31671174 and 31971075 [to LZ]).

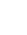

40 1 42 43 4 


\section{Abstract}

Mutations in some cell adhesion molecules (CAMs) cause abnormal synapse formation and maturation, and serve as one of the potential mechanisms of autism spectrum disorders (ASDs). Recently, DSCAM (Down syndrome cell adhesion molecule) was found to be a high-risk gene for autism. However, it is still unclear how DSCAM contributes to ASD. Here, we show that DSCAM expression was downregulated following synapse maturation, and that DSCAM deficiency caused accelerated dendritic spine maturation during early postnatal development. Mechanistically, the extracellular domain (ECD) of DSCAM interacts with neuroligin1 (NLGN1) to block the NLGN1-neurexin1 $\beta$ (NRXN1ß) interaction. DSCAM-ECD was able to rescue spine overmaturation in DSCAM knockdown neurons. Precocious spines in DSCAM-deficient mice showed increased glutamatergic transmission in the developing cortex and induced autism-like behaviors such as social novelty deficits and repetitive behaviors. Thus, DSCAM might be a repressor that prevents premature spine maturation and excessive glutamatergic transmission, and its deficiency could lead to autism-like behaviors. Our study provides new insight into the potential pathophysiological mechanisms of ASDs.

Keywords: Autism, dendritic spine, DSCAM, NLGN1

\section{Significance statement:}

DSCAM is not only associated with Down syndrome but is also a strong autism risk 
68

69

70

71

72 (1) 83 5 86 87 8 89

gene based on large-scale sequencing analysis. However, it remains unknown exactly how DSCAM contributes to autism. In mice, either neuron- and astrocyte-specific or pyramidal neuron-specific DSCAM deficiencies resulted in autism-like behaviors and enhanced spatial memory. In addition, DSCAM knockout or knockdown in pyramidal neurons led to increased dendritic spine maturation. Mechanistically, the extracellular domain of DSCAM binds to NLGN1 and inhibits NLGN1-NRXN1 $\beta$ interaction, which can rescue abnormal spine maturation induced by DSCAM deficiency. Our research demonstrates that DSCAM negatively modulates spine maturation, and that DSCAM deficiency leads to excessive spine maturation and autism-like behaviors, thus providing new insight into a potential pathophysiological mechanism of autism.

(1) 82

\section{(1)}


91 Introduction

Proper synapse connections are crucial for the precise assembly of neural circuitry and for normal brain function. Dysregulation of synapse formation and maturation is associated with a variety of neurodevelopmental disorders, including autism spectrum disorders (ASDs) (Forrest et al., 2018). Cell adhesion molecules (CAMs), which are cell surface proteins that mediate cell-cell interactions, play an essential role in neural development, especially in synaptic development and function (Dalva et al., 2007). ASDs manifest with deficits in social interaction and communication, as well as in increased repetitive or restrictive behaviors (Huguet et al., 2013; Huguet et al., 2016). However, the etiology underlying ASDs at the molecular, cellular and system levels remains elusive. ASDs are highly heritable diseases (Bailey et al., 1995; Autism Genome Project et al., 2007; Rosenberg et al., 2009). Many genes have been identified as risk factors for ASDs (Bourgeron, 2015). A prominent group among these genes is the set of genes that encode CAMs, such as neuroligins (NLGNs) and neurexin1 (NRXN1). At the cellular and molecular levels, dysfunction of neuronal CAMs is regarded as one of the potential mechanisms of ASDs (Chen et al., 2015). Mice with mutations of these CAMs display autism-like behaviors and deficits in synapse formation and maturation (Sudhof, 2008). However, it remains unknown how these ASDs-related CAMs impact synapse development. Recently, DSCAM (Down syndrome cell adhesion molecule) was found to be one of the genetic risk factors for autism in a large-scale genome-wide association study (GWAS) (Satterstrom et al., 
2020). Further research, including whole-genome sequencing (De Rubeis et al., 2014; Yuen et al., 2017), exome sequencing (Iossifov et al., 2014; Ronemus et al., 2014), and targeted sequencing (Stessman et al., 2017), has shown that DSCAM is a strong autism risk gene. In some ASD patients, DSCAM mutations resulted in premature termination (Iossifov et al., 2014; Wang et al., 2016; Stessman et al., 2017; Yuen et al., 2017), suggesting that DSCAM loss-of-function variants may cause ASD.

DSCAM is a cell adhesion protein that is highly expressed in the developing nervous system and that plays a vital role in neural development (Yamakawa et al., 1998; Agarwala et al., 2001a; Agarwala et al., 2001b; Fuerst et al., 2008; Fuerst et al., 2009). In Drosophila, alternative splicing generates thousands of dscam isoforms, which all regulate dendritic self-avoidance and mosaic tiling (Schmucker et al., 2000; Hughes et al., 2007; Matthews et al., 2007; Hattori et al., 2008). Due to the lack of extensive alternative splicing in vertebrates, DSCAM has only two paralogs, DSCAM and DSCAM-like-1 (DSCAML1) (Agarwala et al., 2001b). In vertebrates, DSCAM paralogs play a similar regulatory role in neurite arborization, dendritic self-avoidance and mosaic tiling (Fuerst et al., 2008; Fuerst et al., 2009). Moreover, DSCAM plays a critical role in synapse development. In Drosophila, dscam was reported to regulate precise synaptic targeting (Millard et al., 2010), and dysregulated dscam levels resulted in altered presynaptic size (Kim et al., 2013; Sterne et al., 2015). Additionally, dscam is involved in mediating de novo and learning-related synapse formation in diverse biological models, including chicks and Aplysia (Yamagata and Sanes, 2008; Li et al., 2009). Disruption of glutamatergic transmission and plasticity has been 
134

previously documented in DSCAM ${ }^{2 \mathrm{~J}}$-deficient intracortical circuits of the motor cortex, as well as in spinal interneuronal circuits (Thiry et al., 2016; Laflamme et al., 2019). Despite DSCAM's abundance in the brain and its modulation of diverse physiological functions, little is known about how it regulates synapse development in mammals. Therefore, we hypothesized that DSCAM mediates synapse development and that its deficiency can cause autism.

Here, we examined the expression pattern of DSCAM during postnatal synapse formation and maturation, observed the effects of DSCAM deficiency on dendritic spine development, and investigated its potential as an underlying mechanism of ASD. Furthermore, we generated DSCAM-deficient mice to validate whether the deletion of DSCAM in neurons would result in abnormal spine maturation and altered synaptic transmission, as well as autism-like behaviors. These findings describe a novel pathophysiological role of DSCAM in ASDs.

\section{Materials and Methods}

\section{Animals}

Floxed DSCAM mouse (C57BL/6) was a kind gift from Dr. Jane Y Wu (Institute of Biophysics, Chinese Academy of Science). GFAP::Cre (Jackson Laboratory) transgenic (tg) mouse was purchased from Jackson Laboratory, and NEX-Cre mouse was a kind gift from Dr. Yu-Qiang Ding (Institutes of Brain Science, Fudan University). Primers for genotyping are listed below. Behavior tests were performed with 2 3-month male mice. All mice were housed in a constant temperature and humidity 
156

157

158

159

160

161

chamber at $23{ }^{\circ} \mathrm{C}$, and sufficient food and water were administered daily. No more than 5 adult mice per cage were subjected to a 12 -h light/dark cycle under standard conditions. All the mice were guaranteed to be hygienic. The animal experiments were carried out following the "Guidelines for the Care and Use of Laboratory Animals" promulgated by Nanchang University. Primers for mice genotyping are as below.

\begin{tabular}{|c|c|c|}
\hline Primers & Sequence $\left(5^{\prime} \rightarrow 3^{\prime}\right)$ & Size \\
\hline \multirow[t]{2}{*}{ PP 1} & АССТСССАСАAАСАAACCAG & Wt $=396 b p$ \\
\hline & TGCAGAAGAGTCAAGGCACA & Floxed $=504 \mathrm{bp}$ \\
\hline \multirow[t]{2}{*}{ PP 2} & AGACAGGAGGGTACAGAGGA & $\mathrm{Wt}=457 \mathrm{bp}$ \\
\hline & GTTGTGACTTTAGGGTTATG & Floxed $=565 \mathrm{bp}$ \\
\hline \multirow[t]{2}{*}{ PP 3} & GCTTGCTCATGTGAGCTGGA & \multirow[t]{2}{*}{ Floxed $=420 \mathrm{bp}$} \\
\hline & GGCTGGACGTAAACTCCTC & \\
\hline \multirow[t]{2}{*}{ PP 4} & TCTGAGGCGGAAAGAACCAG & \multirow[t]{2}{*}{ Floxed $=306 \mathrm{bp}$} \\
\hline & GCAGCTGAGAGCAAGTCTCACTG & \\
\hline \multirow[t]{2}{*}{ PP 5} & GCTTGCTCATGTGAGCTGGA & \multirow[t]{2}{*}{$\mathrm{Wt}=446 \mathrm{bp}$} \\
\hline & GCAGCTGAGAGCAAGTCTCACTG & \\
\hline \multirow{2}{*}{$\begin{array}{c}\text { PP } 6 \\
\text { (GFAP-Cre) }\end{array}$} & АСТССТTСАTAA AGСССТ & \multirow[t]{2}{*}{$\operatorname{Tg}=190 \mathrm{bp}$} \\
\hline & ATCACTCGTTGCATCGACCG & \\
\hline PP 7 & GAGTCCTGGAATCAGTCTTTTTC & Cre $=550 \mathrm{bp}$ \\
\hline (NEX-Cre) & ATC ACTCGTTGCATCGACCG & $\mathrm{Wt}=770 \mathrm{bp}$ \\
\hline
\end{tabular}




\section{Quantitative real-time PCR (qRT-PCR) analysis}

Cortical total RNA was purified from WT mice with Trizol reagent (Invitrogen, NY,

USA). 500 ng of total RNA were reverse transcribed to cDNA with oligo (dT) primers.

cDNAs were used as the template in $\mathrm{qPCR}$ in a $20 \mu \mathrm{L}$ reaction system containing

SYBR GreenER qPCR mix (Invitrogen, NY, USA) with gene-specific primers as below.

GAPDH was used as a reference in each sample.

\begin{tabular}{|c|c|}
\hline Primers & \multicolumn{1}{|c|}{ Sequence $\left(5^{\prime} \rightarrow 3^{\prime}\right)$} \\
\hline NLGN1-F & TGATGGGAGTGTCTTGGCAAGC \\
\hline NLGN1-R & CCGTAGTTTCCTTTGGCAGCCT \\
\hline NLGN2-F & CGATGTCATGCTCAGCGCAGTA \\
\hline NLGN2-R & CCACACTACCTCTTCAAAGCGG \\
\hline NLGN3-F & ATCGGTGCATCCTGTGTCAGTC \\
\hline NLGN3-R & CACTGGTTGGTAGTTCACAGCC \\
\hline NLGN4-F & GTGGTGATGACCTACTGGACGA \\
\hline NLGN4-R & GCAGATAGAGCTGGTCTTTGGG \\
\hline SALM2-F & GGCATCCGTATGTACCAAGTGC \\
\hline SALM2-R & GCCAGGTCATTCACTAGGAAGG \\
\hline SALM4-F & AGGCATCCGCATGTACCAGATC \\
\hline SALM4-R & TCAGGGAGGAGCGACTGTC \\
\hline
\end{tabular}




\begin{tabular}{|c|c|}
\hline MDGA1-F & ACCAGTGCCTGACCTCAGCATA \\
\hline MDGA1-R & TTGCCACGAACTTCGCACTGGA \\
\hline MDGA2-F & CAAGAGAAGCCTTGGTGCAGCT \\
\hline MDGA2-R & CAGCACTCGTATTGGATAGGCTC \\
\hline NRXN1-F & ACCGTGCCTTAGCAATCCTTGC \\
\hline NRXN1-R & GTCGTAGCTCAAAACCGTTGCC \\
\hline CNTNAP2-F & GTGATGAGACAGGATACAGCGG \\
\hline CNTNAP2-R & AGTGGTCCACTGCCATCAGGAT \\
\hline CNTN4-F & CTCCAGCAGAATCCGCACTAAG \\
\hline CNTN4-R & СTCCATTCTGGTACTCTCGTGAC \\
\hline CNTN6-F & СTCTGTTGCTGCGGACCTGATT \\
\hline CNTN6-R & GTTGTCAGGTCCTGGTCTCCAA \\
\hline DSCAM-F & CATCCGCATGTACGCCAAGAAC \\
\hline DSCAM-R & GAGATGAGGTGGGTTCCAAGTG \\
\hline$\beta$-catenin-F & GTTCGCCTTCATTATGGACTGCC \\
\hline$\beta$-catenin-R & ATAGCACCCTGTTCCCGCAAAG \\
\hline $\mathrm{N}$-cadherin-F & CCTCCAGAGTTTACTGCCATGAC \\
\hline $\mathrm{N}$-cadherin-R & CCACCACTGATTCTGTATGCCG \\
\hline NrCAM-F & GCAGAGTGAAACATGACCACACC \\
\hline NrCAM-R & GTGTAGGTTCCGCCATCGTCAT \\
\hline NCAM-F & GGTTCCGAGATGGTCAGTTGCT \\
\hline
\end{tabular}




\begin{tabular}{|c|l|}
\hline NCAM-R & CAAGGACTCCTGTCCAATACGG \\
\hline LRRTM2-F & GCCATCGACTTGACAGTGTTCG \\
\hline LRRTM2-R & AACGGTCGTGAGGGATTTCAGG \\
\hline LRRTM1-F & CGGCTTGTTCAAGCTCACAGAG \\
\hline SYNCAM-F & CCACAATGGCAACCTTATTCCGC \\
\hline SYNCAM-R & GCTTCTGCTGTTGCTCTTCTCC \\
\hline GAPDH-F & GACTTGGCAACTGATGGTCGCA \\
\hline GAPDH-R & CATCACTGCCACCCAGAAGACTG \\
\hline PSD-95-F & ATGCCAGTGAGCTTCCCGTTCAG \\
\hline PSD-95-R & TCAGACGGTCACGATCATCGCT \\
\hline SYN-F & GTTGCTTCGCAGAGATGCAGTC \\
\hline SYN-R & TATGCCACTGCTGAGCCCTTCA \\
\hline
\end{tabular}

Subcellular fractionation

171 Mouse brain subcellular fractionation was performed as described previously with

172 modifications (Wang et al., 2018). The cerebral cortices from adult mice were

173 homogenized in 10 volumes (vol) of HEPES-buffered sucrose (0.32 M sucrose, $4 \mathrm{mM}$

$174 \mathrm{HEPES} / \mathrm{NaOH}, \mathrm{pH}$ 7.4) with a glass-Teflon homogenizer. The homogenate was

175 centrifuged at $1,000 \mathrm{~g}$ for $10 \mathrm{~min}$ to remove the nuclear fraction and unbroken cells.

176 The supernatant (S1) was then centrifuged at $10,000 \mathrm{~g}$ for 15 min to yield the crude 
synaptosomal fraction (P1) and the supernatant (S2). The P1 pellet was resuspended in $10 \mathrm{vol}$ of HEPES-buffered sucrose and then centrifuged at 10,000 $\mathrm{g}$ for another 15 min. The resulting pellet (P2) was lysed by hypo-osmotic shock in water, rapidly adjusted to 4 mM HEPES, and mixed continuously for 30 min (on ice). The lysate was then centrifuged at $25,000 \mathrm{~g}$ for $20 \mathrm{~min}$ to yield the supernatant (S3, crude synaptic vesicle fraction) and the pellet (P3, lysed synaptosomal membrane fraction). The P3 pellet was resuspended in HEPES-buffered sucrose, carefully layered on top of a discontinuous gradient containing 0.8-1.0-1.2 M sucrose (top to bottom), and centrifuged at 150,000 $\mathrm{g}$ for $2 \mathrm{~h}$. Optional step. The S3 was centrifuged at $165,000 \mathrm{~g}$ for $2 \mathrm{~h}$ to get the synaptic vesicle protein (SV). The sucrose gradient yielded a floating myelin fraction (G1), a light membrane fraction at the $0.8 \mathrm{M} / 1.0 \mathrm{M}$ sucrose interface (G2), a synaptosomal plasma membrane (SPM) fraction at the 1.0 M/1.2 M sucrose interface (G3), and a mitochondrial fraction as the pellet (G4). The G3 layer was collected, and an equal volume of HEPES-buffered sucrose was added to centrifuge at $20,000 \mathrm{~g}$ for $15 \mathrm{~min}$ in order to obtain SPM. The SPM was resuspended with 1\% Triton X-100 in $50 \mathrm{mM}$ HEPES/NaOH $(\mathrm{pH} 8)$ on ice for 15 min and then centrifuged at $36,000 \mathrm{~g}$ for $15 \mathrm{~min}$ to yield the supernatant (presynaptic membrane protein, Pre) and the pellet (postsynaptic density, PSD), which was solubilized in 2\%SDS PBS buffer at RT.

\section{Plasmids and shRNA construction}

The constructs expressing full-length mouse DSCAM with a C-terminal His-tag and 
199

200

201

202

203

204

205

human DSCAM were purchased from Addgene. To generate the construct expressing secretable ECD of DSCAM (FLAG-ECD), mouse DSCAM cDNA encoding 24-1594 amino acids without signal peptide was amplified by PCR and subcloned into PLP2 (new prolactin leader peptide)-FLAG-pCMV6-XL4 downstream of an artificial signal peptide sequence and a FLAG epitope. The constructs of mouse NRXNs (1 $\alpha-3 \alpha$ and $1 \beta)$ and NLGNs (1-4) were purchased from Origene. Myc-tagged secretable NRXN1 $\beta-E C D$ was subcloned from full length NRXN1 $\beta$. For gene knockdown by RNA interference (RNAi), pSUPER vector (OligoEngine) - based small hairpin RNAs (shRNAs) of mouse DSCAM (sh-DSCAM) and DSCAM scramble (sh-control) were constructed. The target sequence of sh-DSCAM was obtained from a previous report: 5'-GTGGGAGAGGAAGTGATAT-3' (Ly et al., 2008). The sh-control sequence was 5'-AGAGTGGACGTCGATGATTAT 3'. The authenticity of all constructs was verified by DNA sequencing and western blotting analysis.

\section{Cell culture and transfection}

Human embryonic kidney (HEK) 293 cells and COS-7 cells (African green monkey kidney fibroblast cells) were cultured in Dulbecco's modified Eagle's medium (DMEM) (Gibco) supplemented with $10 \%$ fetal bovine serum (FBS) (Gibco). Transient transfection was performed using polyethylenimine (PEI) (Sigma, 408727), as described before(Chen et al., 2021). Briefly, cells were cultured in $100 \mathrm{~mm}$ dishes and at $\sim 70 \%$ confluence, they were incubated with precipitates formed by $5 \mu \mathrm{g}$ of plasmid DNA and $280 \mu \mathrm{L}$ of $0.05 \% \mathrm{PEI}$ (wt/vol). Cells were harvested 24 48 $\mathrm{h}$ 
post-transfection.

222 Cultures of primary hippocampal neurons were prepared from embryonic day (E) 18

223 Sprague-Dawley rats as described previously (Chen et al., 2021). Briefly, hippocampi were isolated and kept separate from one another in HBSS on ice. Following digestion in $0.25 \%$ trypsin plus $0.1 \mathrm{mg} / \mathrm{mL}$ DNase I (one hippocampus in $1 \mathrm{~mL}$ ) at $37{ }^{\circ} \mathrm{C}$ for $20 \mathrm{~min}$, dissociated cells were resuspended in plating media (DMEM supplemented with $10 \%$ FBS) and plated at a density of $1 \times 10^{5}$ or $2 \times 10^{5}$ per well onto poly-D-lysine-coated 20-mm coverslips (WHB) in 12-well plates (Corning). Cells were incubated for $4 \mathrm{~h}$ before replacing with maintenance medium [neurobasal medium (Gibco) supplemented with 2\% B-27 supplement (Gibco), 1\% GlutaMax

\section{Cell surface binding assay}


into HEK293 cells. After 24 h, the medium was changed to conditional medium (CM) containing $0.5 \%$ fetal bovine serum for another $24 \mathrm{~h}$. Then the CM were collected for immunoprecipitation with the tag antibody and Protein A/G beads. Beads were washed with tris-buffered saline (TBS) (50mM Tris $\mathrm{HCl}, 150 \mathrm{mM} \mathrm{NaCl}, \mathrm{pH} 8.0)$ buffer three times, then five packed beads volumes of $0.1 \mathrm{M}$ glycine $\mathrm{HCl}$ buffer $(\mathrm{pH} 3.0)$ were added. Samples were incubated with gentle shaking for $5 \mathrm{~min}$ at room temperature. They were then centrifuged at $2500 \mathrm{rpm}$ for $5 \mathrm{~min}$ to harvest the supernatant. Afterwards, $10 \mu \mathrm{l}$ of $0.5 \mathrm{M}$ Tris $\mathrm{HCl}, \mathrm{pH} 8.0$, with $1.5 \mathrm{M} \mathrm{NaCl}$, was added.

For surface binding assay, HEK293 or COS-7 cells were transfected with indicated constructs. After $24 \sim 48 \mathrm{~h}$, purified protein or CM were added to the transfected cells for $1 \mathrm{~h}$-incubation at $4^{\circ} \mathrm{C}$, and then the cells were subjected to immunostaining with indicated antibodies.

\section{Cell aggregation assay}

As described previously (Boucard et al., 2012), HEK293 cells were transfected with indicated constructs, respectively. After $48 \mathrm{~h}$, the cells were trypsinized and the green cells were then mixed with red cells to incubate with gentle agitation at room temperature with DMEM supplemented with 10\% FBS, 50 mM HEPES-NaOH, pH 7.4, $10 \mathrm{mM} \mathrm{CaCl}$, and $10 \mathrm{mM} \mathrm{MgCl}_{2}$. After 0.5-1 h, the cell mixtures were transferred gently into a 12-well plate and imaged by fluorescence microscopy. The resulting images were analyzed by counting the number of aggregation particles in the field by ImageJ. Cell aggregation particles were defined as four or more clustered cells with at 
least one red and one green cell.

Time-lapse imaging and analysis of dendritic spines

Live imaging of cultured neurons was performed as described previously with modifications (Li et al., 2017). Cultured rat hippocampal neurons were transfected by calcium phosphate precipitation at DIV9 and subjected to live imaging at DIV15. Z-stack images of secondary dendrites from transfected neurons were imaged every minute for 30 min, using an Olympus FV1000 confocal microscope with a $40 \times$ (NA1.35) objective for time-lapse imaging. Images were collapsed into 2D projections and analyzed with ImageJ software. Stable spines were defined as protrusions with stable morphology during the entire imaging session; newborn spines were those with emerging protrusions after imaging, regardless of the time they emerged and whether they persisted during the entire imaging session; eliminated spines were spines that were present at the beginning of imaging but then disappeared during the imaging session.

\section{Immunoprecipitation}

Immunoprecipitation was performed as described previously (Chen et al., 2021). Transfected HEK293 cells were lysed in IP buffer containing (in millimoles): 20 Tris, pH7.6, $50 \mathrm{NaCl}, 1$ EDTA, $1 \mathrm{NaF}, 0.5 \%$ Nonidet P-40 (vol/vol), with protease and phosphatase inhibitors. Samples were centrifuged at $12,000 \times \mathrm{g}$ for $20 \mathrm{~min}$ at $4{ }^{\circ} \mathrm{C}$ to remove debris. Lysates (1 2 mg) or CM were incubated with corresponding antibody 
$(1 \sim 2 \mu \mathrm{g})$ at $4{ }^{\circ} \mathrm{C}$ for either $3-4 \mathrm{~h}$ or overnight and then incubated with $10 \sim 15 \mu \mathrm{L}$ Protein A/G magnetic agarose beads (Pierce) at $4{ }^{\circ} \mathrm{C}$ for $1 \mathrm{~h}$. Samples were washed with IP buffer and resuspended in SDS sample buffer. Then the samples were subjected to WB.

\section{Western blotting}

For protein expression detection, tissues were homogenized in PBS plus protease and phosphatase inhibitors. Then the homogenates were lysed in equal volume of 2 $\times$ RIPA buffer [0.2\% SDS (wt/vol), 1\% sodium deoxycholate (wt/vol) and $2 \%$ Nonidet P-40 ( $\mathrm{vol} / \mathrm{vol})$ in PBS] plus protease and phosphatase inhibitors. Lysates were centrifuged at $12,000 \times \mathrm{g}$ for $20 \mathrm{~min}$ at $4^{\circ} \mathrm{C}$ to remove debris. The supernatants were subjected to Bradford assay (Pierce) to measure protein concentration and diluted in SDS sample buffer. Protein samples $(10 \sim 20 \mu \mathrm{g})$ were resolved by SDS-PAGE and transferred to PVDF membrane (Millipore). The membrane was immunoblotted with primary and secondary antibodies, and immunoreactive bands were visualized by enhanced chemiluminescence under the gel documentation system (Bio-Rad). Densitometric quantification of protein band intensity was performed using ImageJ. Antibodies were diluted with primary antibody dilution buffer (TBS + 1\%TritonX-100 + 5\%BSA) for western blotting (WB). Antibodies used in this manuscript are as below.

\begin{tabular}{|l|l|l|l|}
\hline Target protein & Host species & Source and Cat\# & Dilution \\
\hline DSCAM & Goat & Millipore (AF3666) & $1: 500$ \\
\hline
\end{tabular}




\begin{tabular}{|l|l|l|l|}
\hline PSD-95 & Mouse & Millipore (MAB1598) & $1: 1000$ \\
\hline B-Actin & Rabbit & Millipore (MABT523) & $1: 2000$ \\
\hline FLAG & Mouse & Sigma (1804) & $1: 2000$ \\
\hline NeuN & Mouse & Millipore (MAB377) & $1: 1000$ \\
\hline GFP & Mouse & Santa Cruz (SC-9996) & $1: 1000$ \\
\hline PV & Mouse & Swant (235) & $1: 10000$ \\
\hline His & Rabbit & Santa Cruz (SC-8036) & $1: 1000$ \\
\hline myc & Mouse & Santa Cruz (SC-40) & $1: 500$ \\
\hline NLGN1 & Mouse & Neuromap (75-160) & $1: 500$ \\
\hline NLGN1 & Sheep & ThermoFisher (PA5-48050) & $1: 500$ \\
\hline Synaptophysin & Rabbit & Proteintech (17785-1-AP) & $1: 1000$ \\
\hline Tublin & Rabbit & Santa Cruz (sc-23948) & $1: 2000$ \\
\hline Synapsin I & Mouse & Cell signaling (D12G5) & $1: 200$ \\
\hline
\end{tabular}

Immunostaining

308 Immunostaining of cultured neurons was performed as described previously with modifications (Chen et al., 2021). Primary neurons were fixed with $4 \%$ paraformaldehyde (PFA) / 4\% sucrose (wt/vol) for $15 \mathrm{~min}$. After washing three times with PBS, neurons were incubated with primary antibody diluted in GDB buffer (30 $\mathrm{mM}$ phosphate buffer, $\mathrm{pH} 7.4$, containing $0.2 \%$ gelatin, $0.6 \%$ Triton $\mathrm{X}-100$, and $0.9 \mathrm{M}$ $\mathrm{NaCl})$ at $4{ }^{\circ} \mathrm{C}$ overnight. After washing three times with washing buffer (20 mM 
314 phosphate buffer and $0.5 \mathrm{M} \mathrm{NaCl}$ ), neurons were incubated with the corresponding

315 Alexa Fluor-conjugated secondary antibodies (diluted in GDB buffer) at room

316 temperature for $1 \mathrm{~h}$. The images were obtained by FSX100 (Olympus).

317 Immunostaining of brain slices was performed as described previously (Wang et al., 318 2018). Mice were deeply anesthetized with isoflurane and perfused with PBS followed

319 by $4 \%$ paraformaldehyde (PFA). Brains were postfixed in $4 \%$ PFA at $4{ }^{\circ} \mathrm{C}$ overnight

320 and dehydrated using $30 \%$ sucrose at $4{ }^{\circ} \mathrm{C}$ for $2 \mathrm{~d}$. Brain samples were rapidly frozen

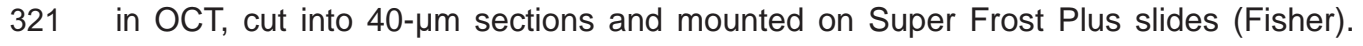

Sections were blocked and permeabilized in PBS containing 0.5\% Triton X-100 and 5\% goat serum for $2 \mathrm{~h}$ at room temperature. Sections were incubated at $4{ }^{\circ} \mathrm{C}$ overnight secondary antibodies. The images were obtained by FSX100 (Olympus).

Golgi Staining.

Golgi staining was performed using the FD Rapid GolgiStain Kit following the manufacturer's protocol (FD Rapid GolgiStainTM Kit, cat: PK401). Brain tissues were incubated in mixed solutions A and B for 2 weeks in the dark at room temperature and solution C for $3 \mathrm{~d}$. Tissues were cut into slices with $80-100 \mu \mathrm{m}$ thickness, stained with solutions $\mathrm{D}$ and $\mathrm{E}$, dehydrated in gradient ethanol, cleared with xylene, and mounted on slides for imaging. Images of neurons in sensory cortex L2/3 were taken and imported into ImageJ with NeuronJ plugin for analysis. Dendrites were reconstructed 
and analyzed using the ImageJ with Sholl Analysis plugin, with $10-\mu \mathrm{m}$ incremental increases in concentric circular diameter from the soma. The images were obtained by FSX100 (Olympus).

\section{Electrophysiological Analysis.}

Brain slices recording was performed as described previously (Wang et al., 2018). Male mice at P12, P21 or P42 were anesthetized with isoflurane (RWD Life Science). Brains were quickly removed to ice-cold oxygenated $\left(95 \% \quad \mathrm{O}_{2} / 5 \% \quad \mathrm{CO}_{2}\right)$ cutting solution containing: $120 \mathrm{mM}$ Choline Chloride, $2.5 \mathrm{mM} \mathrm{KCl}, 7 \mathrm{mM} \mathrm{MgCl}$, $0.5 \mathrm{mM}$ $\mathrm{CaCl}_{2}, 1.25 \mathrm{mM} \mathrm{NaH}_{2} \mathrm{PO}_{4}, 26 \mathrm{mM} \mathrm{NaHCO}_{3}$, and $25 \mathrm{mM}$ glucose. Lamellar $300 \mu \mathrm{m}$ slices of the cortex were cut using VT-1000S Vibratome (Leica Microsystems). The slices were recovered in oxygenated artificial cerebrospinal fluid (ACSF) for 30 min at $32{ }^{\circ} \mathrm{C}$ and maintained at room temperature $\left(25 \pm 1{ }^{\circ} \mathrm{C}\right)$ for an additional $1 \mathrm{~h}$ before recording. The ACSF containing: $124 \mathrm{mM} \mathrm{NaCl}, 2.5 \mathrm{mM} \mathrm{KCl,} 2 \mathrm{mM} \mathrm{MgSO}$, $2.5 \mathrm{mM}$ $\mathrm{CaCl}_{2}, 1.25 \mathrm{mM} \mathrm{NaH}_{2} \mathrm{PO}_{4}, 26 \mathrm{mM} \mathrm{NaHCO}_{3}$, and $10 \mathrm{mM}$ glucose. All solutions were saturated with $95 \% \mathrm{O}_{2} / 5 \% \mathrm{CO}_{2}$ ( $\left.\mathrm{vol} / \mathrm{vol}\right)$.

Slices were placed in the recording chamber, which was superfused ( $2 \mathrm{~mL} / \mathrm{min})$ with ACSF at $32 \sim 34{ }^{\circ} \mathrm{C}$. Pyramidal neurons from sensory cortex L2/3 were visualized with infrared optics using an upright microscope equipped with a 40× water-immersion lens (FN-S2N, Nikon) and an infrared CCD camera (IR-1000, DAGE-MTI). Pipettes were pulled by a micropipette puller (P-1000; Sutter Instrument) with a resistance of 3 5 M $\Omega$. The recording was performed with the MultiClamp 700B amplifier and 1550A 
digitizer (Molecular Device). Series resistance was below $20 \mathrm{M} \Omega$ and monitored throughout the experiments.

For mEPSCs recording, pyramidal neurons were held at $-70 \mathrm{mV}$ in the presence of 20 $\mu \mathrm{M}$ bicuculline (Tocris Bioscience), with the pipette solution containing: $125 \mathrm{mM}$ K-gluconate, 5 mM KCl, 10 mM HEPES, 0.2 mM EGTA, 1 mM MgCl 2,4 mM Mg-ATP, $0.3 \mathrm{mM}$ Na-GTP, and $10 \mathrm{mM}$ phosphocreatine (pH 7.35, 290 295 mOsm). mEPSCs were recorded in the presence of $1 \mu \mathrm{M}$ TTX.

For mIPSCs recording, pyramidal neurons were held at $-70 \mathrm{mV}$ in the presence of 20 $\mu \mathrm{M}$ CNQX (Sigma) and $100 \mu \mathrm{M}$ DL-AP5 (Tocris Bioscience), with the pipette solution containing: 130 mM CsCl, 5 mM Cs-methanesulfonate, 10 mM HEPES, 0.2 mM EGTA, 1 $\mathrm{mM} \mathrm{MgCl} 2,4 \mathrm{mM}$ Mg-ATP, $0.3 \mathrm{mM}$ Na-GTP, $10 \mathrm{mM}$ phosphocreatine and $5 \mathrm{mM}$ QX-314 (pH 7.35, 290 295 mOsm). mIPSCs were recorded in the presence of $1 \mu \mathrm{M}$ TTX. and filled with the solution contained (in millimoles): $125 \mathrm{Cs}$-methanesulfonate, $5 \mathrm{CsCl}$, 10 HEPES, 0.2 EGTA, $1 \mathrm{MgCl}_{2}, 4$ Mg-ATP, 0.3 Na-GTP, 10 phosphocreatine, and 5 QX314 (pH 7.4, 285 mOsm). All the chemicals were purchased from Sigma.

\section{Electron microscopy.}

Electron microscopy studies were performed as described previously with modifications (Yang et al., 2017). Briefly, anesthetized mice were perfused transcardially with PBS and followed by PBS containing $2 \%$ glutaraldehyde and $4 \%$ paraformaldehyde. Brains were postfixed at $4^{\circ} \mathrm{C}$ overnight. Ultrathin sections $(70 \mathrm{~nm})$ of the sensory cortex $\mathrm{L} 2 / 3$ region were cut and stained with $2 \%$ uranyl acetate (vol/vol) 
and Reynolds lead citrate, and they were analyzed with a Hitachi H-7650 transmission electron microscope. Symmetric and asymmetric synapses were visually confirmed and manually counted by investigators unaware of genotypes. Also, synaptic ultrastructural specializations like area, thickness and length of PSD, and presynaptic vesicle numbers were analyzed by investigators blind to genotypes.

\section{Behavioral Analysis.}

Behavioral analysis was carried out with 8- to 10-week-old male mice by investigators unaware of genotypes. Mice were handled for 3 days, and 10 minutes for each day for each one mouse before behavioral tests.

For OFT, mice were placed in a chamber $(50 \times 50 \mathrm{~cm})$. An overhead camera and tracking software (Med Associates) were used to monitor the mouse movement for 10 min. Total distance and time traveled in the center $(15 \times 15 \mathrm{~cm})$ were measured. The chamber was cleaned with $75 \%$ ethanol and wiped with paper towels after each trial. During a 10-min open-field test period, the amount of time spent grooming and the circling behavior were measured manually.

EPM was performed as described previously (Chanques et al., 2018). The platform was elevated $74 \mathrm{~cm}$ above the floor. It consisted of two closed arms $(35 \times 6 \times 22 \mathrm{~cm})$, two open arms $(35 \times 6 \mathrm{~cm})$, and a central zone $(6 \times 6 \mathrm{~cm})$. Mice were placed on the central zone and faced an open arm. Mice could freely explore the platform for $10 \mathrm{~min}$. The total time spent in the open arms and the entries to open arms were recorded by the monitoring software (Med Associates Inc., Farifax, VT). The apparatus was 
cleaned with $75 \%$ ethanol after each trial.

Three-chamber social preference test was performed as described previously with minor modifications (Moy et al., 2004). The apparatus was a transparent Plexiglas rectangular box $(40 \times 72 \mathrm{~cm})$ with three equal transparent partitions $(40 \times 24 \mathrm{~cm})$, including left, right and center chambers. Two wire cups were placed in the left and right chambers for each one. Firstly, the experimental mouse was placed in the center and allowed to freely explore the three chambers for 10-min. After that, an age- and gender-matched stranger C57BL/6J mouse (S1) was placed in one of the two wire cages and on the other side were the empty wire cages (E). Then, the test mouse was placed in the center for another 10-min session. The test mouse would now choose between S1 and E. After that, a second age- and gender-matched C57BL/6J stranger mouse (S2) was placed in another wire cage. Finally, the test mouse was placed in the center for the last 10-min session. Thus, the test mouse would now choose between an already familiar mouse (S1) and a new stranger mouse (S2). The mouse's movement was recorded by a video-tracking system (Med Associates Inc., Farifax, VT). Time spent in each chamber and sniffing time within a $1 \mathrm{~cm}$ distance to each wire cage (interaction time) were measured. Social preference index was calculated as described (Chiang et al., 2018): [interaction time (S1) - interaction time $(E)]$ / [interaction time (S1) + interaction time (E)] for each genotype; [interaction time (S2) - interaction time (S1)] / [interaction time (S2) + interaction time (S1)] for each genotype.

The Barnes circular maze was performed as described previously with modifications 
424 (Rosenfeld and Ferguson, 2014). The Barnes circular maze is a planar, round white 425 Plexiglas platform ( $75 \mathrm{~cm}$ diameter), $1 \mathrm{~m}$ above the floor, with 18 evenly spaced holes 426 (7 cm diameter). A black escape box was placed under one hole. During the trial, a 500-lux light was turned on. After each trial, the platform and the escape box were 
446

447

448

449

450

451

452

453

454

455

456

457

458

459

460

461

462

463

464

465

466

467

Statistical analysis was done by the GraphPad Prism version 7.0 (GraphPad Software). Before being analyzed, all data in our study were checked by the D'Agostino-Pearson omnibus normality test to prove they came from a Gaussian distribution. Two-way ANOVA that analyzes more than two parameters was used in behavioral and body weight studies. All statistical analysis were presented as mean \pm SEM and analyzed by two-tailed Student's t-test or one-way ANOVA, including behavioral tests, morphological analysis, electrophysiological studies and western blotting. For the data that did not conform to the Gaussian distribution, we used Mann-Whitney $U$ test or Kruskal-Wallis test for the statistical analysis. Otherwise, Values of $p<0.05$ were considered statistically significant. Statistical significance was set at ${ }^{*} p<0.05,{ }^{* *} p<0.01$, and ${ }^{* *} p<0.001$.

\section{Results}

\section{DSCAM expression is downregulated during synapse maturation}

CAMs are critical for synapse formation and maturation, and their expression is regulated during this developmental stage (Foldy et al., 2016). To characterize the expression patterns of CAMs during synapse development, we performed qRT-PCR with mRNA extracted from mouse cortex on postnatal days 0 (P0) to 60 (P60) (Fig.1A). As shown in Fig. 1B, the expression of most CAMs, such as NLGNs, increased gradually during this stage, consistent with synapsin I and postsynaptic density (PSD)-95 expression patterns. Intriguingly, unlike synapsin I and PSD-95, the expression of DSCAM increased from P0 to P14, but dramatically decreased 
468

469

470

471

472

473

474 afterward (Fig. 1B). When investigated in vitro, DSCAM protein levels in primary cortical neurons similarly increased from DIV (days in vitro) 3 to DIV12; this phenomenon was also followed by a decrease in DSCAM protein levels (Fig. 1C-1D). Synapse formation commences in the first postnatal week and peaks at P14, and synapse maturation continues thereafter (Farhy-Tselnicker and Allen, 2018). In parallel, the expression of DSCAM in the brain gradually increased from embryonic day 12.5 (E12.5) until it reached its peak at P12, and then decreased until P60 (Fig. $1 E-1 F)$. This expression pattern of DSCAM suggests that its level is downregulated during synapse maturation compared to other CAMs. We also examined the subcellular distribution of DSCAM in mouse brains. PSD fractionation assays revealed that DSCAM was localized to the PSD area (Fig. 1G). To confirm the distribution of DSCAM in neurons, we cotransfected His-tagged full-length DSCAM plus GFP into cultured neurons at DIV9 and stained them with anti-His antibody at DIV17. As shown in Fig. 1H-1J, DSCAM was mainly distributed and clustered in GFP-labeled dendrites and dendritic spines. Dendritic spines are morphologically divided into mature and immature spines. Mature spines are mushroom-like, with a width of spine head to neck ratio $\geq 1.5$; immature spines have a spine head to neck ratio $<1.5$. Interestingly, the fluorescence intensity and size of DSCAM-His puncta were markedly increased in dendritic shafts and in immature spines, compared to those in mature spines. Furthermore, costaining with PSD-95 demonstrated the colocalization of DSCAM-His with PSD-95 (Fig. 1K). Taken together, these results provide an indication of how DSCAM functions in spine maturation. 
491 DSCAM deficiency results in increased spine maturation in the sensory cortex

492 As DSCAM expression was downregulated during the spine maturation period, we 493 were curious as to whether DSCAM deficiency would affect spine density and/or 494 maturation in vivo. A previous study reported that DSCAM-null C57BL/6 mice died 495 within $24 \mathrm{~h}$ of birth (Amano et al., 2009), so we generated DSCAM floxed mice 496 (DSCAM f/f) (Fig. 2A-2B) and crossed them with a hGFAP::Cre line, where Cre is 497 expressed in neural progenitor cells at E13.5 and in all forebrain neurons and 498 astrocytes of mice (Zhuo et al., 2001). Compared to that of control mice (DSCAM f/f), 499 the expression of DSCAM in the brain was abated by approximately $60 \%$ in resulting hGFAP::Cre; DSCAM f/f (hereafter referred to as GFAP-DSCAM f/f) mice (Fig. 2C), in 501 which DSCAM was ablated in neurons and astrocytes. Next, we examined whether 502 DSCAM deficiency could alter neural development. As shown in Fig. 2D-2F, GFAP-DSCAM f/f mice, while displaying a similar body weight to that of control mice (Fig. 21). Neurons in the sensory cortex $L 2 / 3$ receive multiple inputs and are highly plastic; they are involved in context-specific sensory information processing and in controlling the 
512

513

514

515

gain of cortical output (Feldman and Brecht, 2005; Feldman, 2009; Petersen and Crochet, 2013). We used Golgi staining to examine dendritic spine development from P12 to P42 in sensory cortex L2/3 of GFAP-DSCAM f/f mice. As shown in Fig. 3A-3D, the densities of both total and mature spines were greater in GFAP-DSCAM f/f mice than in control mice from $\mathrm{P} 12$ to $\mathrm{P} 42$, while the number of immature spines was greater at P12 and P21, but not P42. Surprisingly, the width of spine heads was also greater at P21 and P42 (Fig. 3E) in GFAP-DSCAM f/f mice. Similar results were observed in sensory cortex L5 (Fig. 3J-3N). As with a previous study (Maynard and Stein, 2012), the dendritic lengths and branches in sensory cortex L2/3 (Fig. 3F-3H) and L5 (Fig. 3O-3Q) were increased in GFAP-DSCAM f/f mice. Dendritic complexity was increased in GFAP-DSCAM f/f mice at P21, but it returned to normal levels by P42 (Fig. 3I and 3R). These results suggest that DSCAM deficiency in forebrain neurons and astrocytes increases mature spine densities and sizes in the sensory cortex.

The size or volume of spine heads is strongly correlated with the PSD area (Harris et al., 1992; Arellano et al., 2007). A larger spine volume indicates a larger PSD area and a stronger synaptic strength (Holtmaat and Svoboda, 2009). To confirm this relationship, we performed electron microscopy (EM) analysis and found that the number of asymmetric (excitatory) synapses was increased in sensory cortex L2/3 in GFAP-DSCAM f/f mice, while the number of symmetric (inhibitory) synapses was unchanged (Fig. 4A-4B). The presynaptic vesicle number was similar in control and GFAP-DSCAM f/f mice (Fig. 4C). However, the area, length, and thickness of the PSD 
534

535

536

537

538

539

540

541

542

543

544

545

546

547

548

549

550

551

552

553

554

555

were all greater in GFAP-DSCAM f/f mice (Fig. 4D-4F). Taken together, these results indicate that DSCAM deficiency increases spine maturation in the sensory cortex.

Glutamatergic transmission is elevated in the $L 2 / 3$ sensory cortex of DSCAM-deficient mice

Dendritic spine density and morphology are critical for synaptic transmission strength and synaptic stability (Alvarez and Sabatini, 2007; Yuste, 2013). An increase in the number of matured spines corresponds to an increase in glutamatergic transmission. We examined whether DSCAM deficiency alters neurotransmission in the cortex during development by recording miniature excitatory postsynaptic currents (mEPSCs) and miniature inhibitory postsynaptic currents (mIPSCs) in sensory cortex L2/3 of GFAP-DSCAM f/f mice at P12, P21, and P42. Notably, GFAP-DSCAM f/f mice displayed an increase in mEPSC frequency at all three time points, but mEPSC amplitudes were not changed (Fig. 5A-5C). Neither mIPSC frequencies nor amplitudes were altered in GFAP-DSCAM f/f mice (Fig. 5D-5F). Together, these results suggest that DSCAM deficiency increases glutamatergic transmission in sensory cortex L2/3.

Knockdown of DSCAM in primary neurons disrupts spine dynamics and maturation

Since DSCAM deficiency results in increased spine maturation, we investigated whether DSCAM modulates spine dynamics by knocking down DSCAM in neurons 
556

557

558

559

560

561

562

563

564

565

566

567

568

569

570

571

572

573

574

575

576

577 via small hairpin RNA (sh-RNA). Based on a previous report (Ly et al., 2008), we constructed sh-RNA for mouse or rat DSCAM (sh-DSCAM) and scrambled sh-RNA for use as a control (sh-control). We then confirmed the knockdown efficiency of sh-DSCAM in HEK293T cells transfected with mouse DSCAM-His (Fig. 6A). Furthermore, we observed and analyzed dendritic spine density in sh-DSCAM-transfected neurons. Compared to that in neurons transfected with sh-control, the total spine density was increased in neurons transfected with sh-DSCAM (Fig. 6B-6C). To exclude the off-target effects of sh-DSCAM, we overexpressed human DSCAM (hDSCAM), which can not be recognized by sh-DSCAM (Fig. 6A), in sh-DSCAM transfected neurons, and we found that hDSCAM overexpression rescued the spine deficits in DSCAM knockdown neurons (Fig. $6 \mathrm{~B}-6 \mathrm{C})$, thus confirming the effects of DSCAM knockdown on spine development. Furthermore, the neurons were stained with anti-PSD-95 antibody to quantify the number and size of PSD-95 puncta. Compared with nontransfected neurons in the same coverslip or sh-control transfected neurons, neurons transfected with sh-DSCAM displayed increased numbers and sizes of PSD-95 puncta (Fig. 6D-6F). These results indicate that knockdown of DSCAM in cultured neurons increases dendritic spine maturation.

Because enhanced spine formation or stabilization leads to increased spine maturation, we performed time-lapse imaging in cultured neurons to observe the dynamic spine maturation process. Cultured cortical neurons were cotransfected with GFP and sh-DSCAM or sh-control at DIV9 and imaged at DIV15 17. The same 
578 secondary dendritic branch was imaged every minute for $1 \mathrm{~h}$, and the percentages of stable, new, and eliminated spines were analyzed. As shown in Fig. 6G-6J, neurons transfected with sh-DSCAM exhibited an increase in stable spines and a decrease in eliminated spines, but they showed no change in the number of new spines during the imaging period compared with neurons transfected with sh-control. In other words, spines were more often stabilized and less often eliminated due to the knockdown of DSCAM. Notably, there was a positive correlation between the percentage of stable spines and spine density and a negative correlation between the percentage of eliminated spines and spine density (Fig. 6K-6M). Taken together, these live imaging data demonstrated that DSCAM knockdown promotes spine stabilization in neurons, thus accelerating spine maturation.

\section{DSCAM interacts with NLGN1}

DSCAM, a single transmembrane protein, belongs to the $\lg$ superfamily of CAMs that plays a critical role in synapse formation and maturation (Sudhof, 2008, 2017). To explore the underlying mechanisms of DSCAM in spine maturation, we examined whether DSCAM interacts with other CAMs. NLGNs, a class of transmembrane proteins that interact in trans with presynaptic NRXNs, are classic postsynaptic CAMs and are essential for synaptogenesis and synapse maturation (Varoqueaux et al., 2006; Chubykin et al., 2007; Sudhof, 2008; Bemben et al., 2015; Sudhof, 2017). We cotransfected DSCAM-His with NLGNs (NLGN1-4) or NRXNs (NRXN1 $\alpha-3 \alpha$ and 1ß) into HEK293T cells and performed coimmunoprecipitation (co-IP) assays. As shown 
600

601

602

603

604

605

606

607

608

609

610

611

612

613

614

615

616

617

618

619

620

621

in Fig. 7A, NLGN1-4 were co-IPed with DSCAM-His, but NRXNs were not. Conversely, DSCAM-His was also co-IPed with NLGNs (Fig. 7B). Moreover, the FLAG-tagged extracellular domain (ECD) of DSCAM (FLAG-ECD) and NLGNs were cotransfected into HEK293T cells for co-IP assay, and FLAG-ECD was co-IPed with NLGNs (Fig. 7C). These results suggest that DSCAM could interact with NLGN1-4 through its ECD. To detect whether DSCAM-ECD binds to cell surface NLGNs, we performed a cell surface binding assay. First, we overexpressed FLAG-ECD in HEK293T cells. To confirm whether FLAG-ECD could be secreted into the medium, we collected conditioned medium (CM) and added anti-FLAG antibody to enrich the secretable FLAG-ECD. As shown in Fig. 7D, FLAG-ECD was detected in IPed CM, as well as in cell lysates. Next, we harvested CM with FLAG-ECD or control and added them to fixed HEK293T cells cotransfected with NLGNs and GFP. After incubation, the cells were subjected to immunostaining with anti-FLAG antibody. As shown in Fig. 7E, FLAG-ECD bound to the surface of cells transfected with NLGNs. In fact, more FLAG-ECD was enriched on the cell surface that expressed NLGN1 than on the cell surfaces that expressed NLGN2-4 (Fig. 7F). Altogether, these results suggest that DSCAM interacts with NLGN1 through their ECDs.

NLGN1 is strongly expressed in excitatory synapses and is implicated in ASDs (Varoqueaux et al., 2006; Sudhof, 2008; Nakanishi et al., 2017; Sudhof, 2017). Next, we focused on the DSCAM-NLGN1 interaction. The endogenous interaction of DSCAM and NLGN1 was confirmed by co-IP with mouse brain lysates (Fig. 7G). We then examined whether DSCAM can regulate NLGN1 expression and distribution in 
622

623

624

625

626

627

628

629

630

631

632

633

634

635

636

637

638

the synaptic area. The protein level of NLGN1 was comparable in the brain between control and DSCAM-deficient mice (Fig. 7H-7I). However, the level of NLGN1 in the synaptosomal plasma membrane (SPM) fraction was increased in GFAP-DSCAM f/f mice (Fig. 7J-7K), suggesting that DSCAM deficiency can induce NLGN1 enrichment in the synaptic membrane.

\section{DSCAM inhibits the NLGN1-NRXN1 $\beta$ interaction}

Postsynaptic NLGN1 is involved in synapse maturation by interacting in trans with presynaptic NRXN1 $\beta$ (Sudhof, 2008). We examined whether DSCAM could regulate the NLGN1-NRXN1 $\beta$ interaction by cotransfecting NLGN1, NRXN1 $\beta$ and DSCAM into HEK293T cells. As shown in Fig. 8A-8B, NRXN1 $\beta$ was co-IPed with NLGN1 in the absence of DSCAM-His. However, NRXN1 $\beta$ co-IP with NLGN1 was decreased in the presence of increased DSCAM-His, suggesting that DSCAM inhibits the NLGN1-NRXN1 $\beta$ interaction. Since NLGN1 binds in trans with NRXN1 $\beta$, we performed cell surface binding assays to detect whether DSCAM could inhibit this trans-cell interaction. COS-7 cells were cotransfected with NLGN1 and varied amounts of DSCAM-His. After transfection, the cells were treated with purified NRXN1 $\beta$-ECD-myc protein for $1 \mathrm{~h}$ and then fixed for immunostaining with anti-NLGN1, anti-myc and anti-His antibodies. As shown in Fig. 8C-8D, the red fluorescence, which indicates cell surface binding of NRXN1ß-ECD-myc, was decreased when DSCAM-His expression was increased. Moreover, we also used cell aggregation assays to confirm the inhibition of NLGN1-NRXN1 $\beta$ trans-cell interactions by DSCAM 
644 (Fig. 8E). Cells clustered when HEK293T cells cotransfected with NLGN1 and GFP 645 were mixed with another set of HEK293T cells cotransfected with NRXN1 $\beta$ and RFP 646 (Fig. 8F). DSCAM-His coexpression with NLGN1 in GFP+ cells decreased the 647 number of aggregates in a dose-dependent manner (Fig. 8F-8G). Taken together, 648 these results suggest that DSCAM inhibits the NLGN1-NRXN1 $\beta$ trans-cell interaction. 649 As DSCAM inhibited the NLGN1-NRXN1 $\beta$ trans-cell interaction through ECD binding 650 to NLGN1, we contemplated whether DSCAM-ECD alone could block the 651 NLGN1-NRXN1 $\beta$ in trans interaction. Using cell aggregation assays, we added CM NLGN1-NRXN1 $\beta$ cell aggregates in a dose-dependent manner. Next, we theorized NLGN1-NRXN1 $\beta$ interactions to inhibit premature spine maturation.

660 in mice Given that DSCAM is one of 102 ASD predominant genes and that its absence accelerated spine maturation and elevated glutamatergic transmission, we next examined the behaviors of DSCAM-deficient mice. First, we conducted autism-associated 
666

667

668

669

670

671

672

673

674

675

676

677

678

679

680

681

682

683

684

685

686

687

behavioral tests in GFAP-DSCAM f/f and control mice. As shown in Fig. 9A-9B, GFAP-DSCAM f/f mice displayed increased amounts of circling and self-grooming than control mice did.

Along with repetitive behaviors, profound social impairment is a core symptom of ASD.

We therefore conducted three-chamber social interaction tests (Fig. 9C-9I) for social recognition and social interaction (Moy et al., 2004). In the social preference test, both GFAP-DSCAM f/f and control mice preferred to explore a stranger mouse (stranger1 mouse, S1) than an inanimate object (empty cage, E), as measured by duration spent in each chamber and duration of sniffing (interaction time) (Fig. 9C-9E). Moreover, the social interaction index was indistinguishable between the two genotypes, suggesting normal social preference in GFAP-DSCAM f/f mice (Fig. 9F). Next, we compared social novelty preference. After the $\mathrm{E}$ was replaced with another stranger mouse (stranger2 mouse, S2), control mice spent more time in the S2 chamber and interacted more with S2 than they did with the familiar mouse (S1) (Fig. 9G-9H). In contrast, GFAP-DSCAM f/f mice spent less time in the S2 chamber than in the S1 chamber (Fig. 9G). Additionally, GFAP-DSCAM f/f mice did not differentiate between S1 and S2 in terms of sniffing duration (Fig. 9H). Social novelty index score was decreased in GFAP-DSCAM f/f mice (Fig. 9l), suggesting an impairment in social novelty but not sociability.

We also conducted the Barnes circular mazes test to examine the impact of DSCAM deficiency on spatial learning and memory (Fig. 9J-90). In the 4-day training session, escape latency and number of errors were similar in both genotype (Fig. 9J-9K), 
688

689

690

691

692

693

694

695

696

697

698

699

700

701

702

703

704

705

706

707

708

709

suggesting normal spatial learning for GFAP-DSCAM f/f mice. However, at test, GFAP-DSCAM f/f mice displayed reduced latency to reach target and greated numbers of correct pokes, but they showed no difference in travel distance and time on target, compared with the controls (Fig. 9L-90), which suggests that DSCAM deletion may enhance spatial memory. Taken together, the data indicate that GFAP-mediated DSCAM deficiency increases stereotyped behaviors, impairs social novelty, and enhances spatial memory.

Moreover, GFAP-DSCAM f/f mice exhibited increased distance traveled and velocity in the open field test (OFT) but decreased time in the center (Fig. 9P-9S). In the elevated plus maze (EPM), GFAP-DSCAM f/f mice entered the open arms less and spent less time in them (Fig. 9T-9W), suggesting increased anxiety-like behaviors due to DSCAM deletion in neurons and astrocytes.

\section{DSCAM deficiency in pyramidal neurons induces premature spine maturation}

\section{and autism-like behaviors}

DSCAM was primarily expressed in neurons, as examined by western blotting with isolated neurons and astrocytes (Fig. 10A), and its expression in cultured neurons was negatively regulated during the postnatal development period (Fig. 1C-1D). We therefore investigated whether the spine and behavioral deficits in GFAP-DSCAM f/f mice could result from DSCAM deficiency in pyramidal neurons. To this end, we crossed DSCAM f/f mice with a NEX-Cre line, in which Cre is expressed in pyramidal neurons of the neocortex and hippocampus. We found that the DSCAM level was 
710

711 Furthermore, the sensory cortex L2/3 of NEX-DSCAM f/f mice at P42 was subjected

712 to Golgi staining. The densities of total spines and mature spines were markedly

713 increased, while the density of immature spines remained unchanged (Fig. 10D-10G).

714 Additionally, the width of spine head increased (Fig. 10H). These results suggest that

715 DSCAM deficiency in pyramidal neurons also lead to spine overmaturation.

716

Next, we examined the behaviors of NEX-DSCAM f/f mice. In the OFT, the duration spent in the center and the velocity were similar between NEX-DSCAM f/f and control mice (Fig. 10I-10L). In the EPM, the NEX-DSCAM f/f mice entered open and closed arms at similar rates as the control mice did, but they reduced the duration spent in open arms (Fig. 10M-10P), suggesting that DSCAM deficiency in pyramidal neurons do not induce anxiety-like behaviors.

In addition, NEX-DSCAM f/f mice were subjected to tests for autism-associated behaviors. NEX-DSCAM f/f mice exhibited stereotyped behaviors (Fig. 11A-11B), social novelty deficits (Fig. 11C-11I) and enhanced spatial memory (Fig. 11J-110). Taken together, these results demonstrate that DSCAM deficiency in pyramidal neurons also induces autism-like behaviors and enhanced spatial memory. Therefore, we propose our DSCAM model of synapse maturation. In control mice, DSCAM was localized to immature spines and interacted with NLGN1 to inhibit the NLGN1-NRXN1 $\beta$ interaction, thus preventing spine overmaturation. In DSCAM-deficient mice, this inhibition of the NLGN1-NRXN1 interaction was removed, and resulting in premature spine maturation, which ultimately led to 
autism-like behaviors and enhanced spatial memory (Fig. 11P).

\section{Discussion}

In this study, we provided evidence that DSCAM serves as a repressor for the NLGN1-NRXN1 $\beta$ interaction, and that its deficiency leads to premature spine maturation and excessive glutamatergic transmission, inducing autism-like behaviors. The major findings of this paper are as follows. First, DSCAM was downregulated following synapse maturation, and knockdown of DSCAM in primary neurons increased spine maturation. Second, in vivo, GFAP-mediated DSCAM deficiency in mice led to spine overmaturation and increased glutamatergic transmission. Third, DSCAM interacted with NLGN1 through its ECD and blocked the NLGN1-NRXN1ß interaction to suppress spine overmaturation. Finally, DSCAM-deficient mice exhibited autism-like behaviors, including impaired social novelty, increased circling and grooming time, and improved spatial memory.

Dendritic spines are small protrusions from the dendrites of excitatory neurons and play critical roles in learning, memory, and cognition (Yuste and Bonhoeffer, 2004; Berry and Nedivi, 2017). Dysregulation of spine development has been implicated in mental disorders including autism, depression and schizophrenia (Forrest et al., 2018). Previous studies have shown that DSCAM acts as a crucial factor or regulator in synapse development and synaptic plasticity (Yamagata and Sanes, 2008; Li et al., 2009; Maynard and Stein, 2012; Thiry et al., 2016; Laflamme et al., 2019), indicating its role in spine development. Here, we found an increase in the density of matured 
754

755

756

757

758

759

760

761

762

763

764

765

766

767

768

769

770

771

772

773

774

775

spines and in the volume of spine heads in GFAP-DSCAM f/f and NEX-DSCAM f/f mice. Due to potential differences in staining efficiency between the two batches of Golgi staining, we observed a small difference in the spine density data for the control mice between Fig. 3B-3D and Fig. 11E-11G. We further confirmed the spine deficits in cultured neurons. Live imaging results showed that increased spine density could be attributed to enhanced stability. These results suggest that DSCAM can downregulate spine maturation in the developing sensory cortex.

Several recent studies reported that DSCAM-ICD plays a critical role in synapse development and neuronal migration (Sachse et al., 2019; Arimura et al., 2020). However, we found that DSCAM interacted with NLGN1 through its ECD to disrupt the NLGN1-NRXN1 $\beta$ interaction. NLGN1 plays an essential role in spine maturation (Varoqueaux et al., 2006; Chubykin et al., 2007; Bemben et al., 2015). DSCAM-ECD also rescued abnormal spine maturation in DSCAM knockdown neurons. Therefore, DSCAM might modulate spine maturation through its ECD. Differences in spine densities have previously been reported in patients with neuropsychiatric disorders, such as increased spine densities in L2 of the cortex and L5 of the temporal lobe in ASD patients (Hutsler and Zhang, 2010). In addition, increased spines were also observed in Fragile-X syndrome patients and correponding mouse models (Comery et al., 1997; Irwin et al., 2000). Thus, dendritic spine malformation may lead to neuronal dysfunction during neural development, and DSCAM may serve as a modulator in spine remodeling.

Disruption of the excitatory/inhibitory (E/I) balance has been implicated in various 
776

777

778

779

780

781

782

783

784

785

786

787

788

789

790

791

792

793

794

795

796

797

neuropsychiatric disorders, including ASD (Rubenstein and Merzenich, 2003; Nelson and Valakh, 2015). Elevation of the E/I ratio in the mouse prefrontal cortex leads to social deficits (Yizhar et al., 2011). In a similar manner, we found that glutamatergic transmission increased in GFAP-DSCAM f/f mice during postnatal development while GABAergic transmission was unchanged, which might result in elevation of the E/I ratio and lead to social novelty deficits (Nelson and Valakh, 2015). Social interaction deficits were found in these DSCAM-deficient mice. Although some ASD mouse models exhibit a reduced E/I ratio, such as mice with autism-associated mutations in NRXNs or SHANKs (Etherton et al., 2009; Jiang and Ehlers, 2013), an enhanced E/I ratio can also be observed in many other ASD mouse models, like TSC1-, MDGA2-, FMRP- or CUL3- deficient mice (Bateup et al., 2013; Zhang et al., 2014; Connor et al., 2016; Dong et al., 2020). Precocious spine maturation in hippocampal neurons dramatically elevated the E/I ratio and impaired the cognitive development in SynGAP mutant mice (Clement et al., 2012). In our autistic model of DSCAM-deficient mice, early spine maturation in DSCAM-deficient neurons contributed to increased excitatory synaptic transmission, which might impair the $E / I$ balance and lead to autism-like behaviors. In addition, DSCAM deficiency increased only mEPSCs frequency, not amplitude, which may account for the normal surface distribution of active AMPARs or NMDARs.

Previous studies have indicated higher cognitive function in patients with macrocephaly and ASD (Courchesne and Pierce, 2005; Sacco et al., 2007). Increased head circumferences have been shown in ASD patients with special 
798

799

800

801

802

803

804

805

806

807

808

809

810

811

812

813

814

815

816

817

818

819

capabilities (Bena et al., 2013). DSCAM-null mice $\left(\right.$ DSCAM $^{\text {del17 }}$ or DSCAM ${ }^{2 J}$ ) similarly exhibited ventricular dilation with a dome-shaped head (Xu et al., 2011; Lemieux et al., 2016). Intriguingly, increased spatial memory was observed in both GFAP-DSCAM f/f and NEX-DSCAM f/f mice along with increased brain weight in this study, which implies that brain enlargement might be one factor explaining the enhanced spatial memory in DSCAM-deficient mice. Relatedly, it was previously theorized that mushroom spines (matured spines) can act as memory spines (Bourne and Harris, 2007). More mature spines might be another explanation for the increased spatial memory. Our live imaging results found a positive correlation between the percentage of stable spines and the spine density, which may also contribute to the enhanced spatial memory demonstrated by DSCAM-deficient mice. It has also been reported that NLGN3-R451C mice (an ASD-associated mutation) displayed enhanced spatial learning in the Morris water maze in addition to autism-like behaviors (Tabuchi et al., 2007). Taken together, our results reveal the regulatory functions of DSCAM in spine maturation and its underlying molecular mechanisms in the nervous system. DSCAM-deficient mice with increased spatial memory might belong to the subset of autism mouse models with high functions.

DSCAM is located on chromosome 21 in humans; an extra copy of chromosome 21 causes Down syndrome (DS) (Saito et al., 2000). Upregulated DSCAM expression is found in the brains of DS patients, DS mouse models, and AD mouse models (Saito et al., 2000; Amano et al., 2004; Jia et al., 2011), causing pathological changes in the brain and finally leading to impairment in cognitive functions. Elevated levels of 
820

821

822

823

824

825

826

827

828

829

830

831

832

833

834

835

836

837

838

839

840

841

DSCAM are also found in post-mortem brains from bipolar subjects (Amano et al., 2008). Likewise, DSCAM expression is higher in intractable epilepsy (IE) patients than in controls (Shen et al., 2011). However, DSCAM deficiency has been found to disrupt dendritic self-avoidance and tiling in the mouse retina and cause abnormal neuronal migration (Fuerst et al., 2008; Fuerst et al., 2009; Sachse et al., 2019; Arimura et al., 2020). Additionally, premature termination mutations of DSCAM are observed in some ASDs patients (Iossifov et al., 2014; Wang et al., 2016; Stessman et al., 2017; Yuen et al., 2017). Our results showed that loss of DSCAM in pyramidal neurons induced autism-like behaviors in mice. Together, all these findings suggest that dysregulated DSCAM expression alters spine maturation, resulting in abnormal synaptic transmission, which may explain how gene-dosage imbalance of DSCAM could potentially contribute to the pathogenesis of neurological DSCAM-related disorders.

\section{Author contributions}

EF and PC conceived and designed the research project. PC, ZL, QZ, DL and H-FJ performed experiments and collected data. PC, ZL, QZ and TZ analyzed data. LS, JL and LZ provided experimental material and contributed to data analysis and discussion. PC, ZL and EF prepared manuscript figures. EF, PC, LZ, B-ML and B-XP wrote the manuscript. XL, SZ and SW provided technical and intellectual support. All authors provided critical reviews of results and approved the manuscript. 


\section{References}

Agarwala KL, Ganesh S, Amano K, Suzuki T, Yamakawa K (2001a) DSCAM, a highly conserved gene in mammals, expressed in differentiating mouse brain. Biochem Biophys Res Commun 281:697-705. Agarwala KL, Ganesh S, Tsutsumi Y, Suzuki T, Amano K, Yamakawa K (2001b) Cloning and functional characterization of DSCAML1, a novel DSCAM-like cell adhesion molecule that mediates homophilic intercellular adhesion. Biochem Biophys Res Commun 285:760-772.

Alvarez VA, Sabatini BL (2007) Anatomical and physiological plasticity of dendritic spines. Annu Rev Neurosci 30:79-97.

Amano K, Sago H, Uchikawa C, Suzuki T, Kotliarova SE, Nukina N, Epstein CJ, Yamakawa K (2004) Dosage-dependent over-expression of genes in the trisomic region of Ts1Cje mouse model for Down syndrome. Hum Mol Genet 13:1333-1340.

Amano K, Yamada K, Iwayama Y, Detera-Wadleigh SD, Hattori E, Toyota T, Tokunaga K, Yoshikawa T, Yamakawa K (2008) Association study between the Down syndrome cell adhesion molecule (DSCAM) gene and bipolar disorder. Psychiatr Genet 18:1-10.

Amano K, Fujii M, Arata S, Tojima T, Ogawa M, Morita N, Shimohata A, Furuichi T, Itohara S, Kamiguchi H, Korenberg JR, Arata A, Yamakawa K (2009) DSCAM deficiency causes loss of pre-inspiratory neuron synchroneity and perinatal death. J Neurosci 29:2984-2996.

Arellano JI, Benavides-Piccione R, Defelipe J, Yuste R (2007) Ultrastructure of dendritic spines: correlation between synaptic and spine morphologies. Front Neurosci 1:131-143.

Arimura N, Okada M, Taya S, Dewa KI, Tsuzuki A, Uetake H, Miyashita S, Hashizume K, Shimaoka K, Egusa S, Nishioka T, Yanagawa Y, Yamakawa K, Inoue YU, Inoue T, Kaibuchi K, Hoshino M (2020) DSCAM regulates delamination of neurons in the developing midbrain. Sci Adv 6.

Autism Genome Project C et al. (2007) Mapping autism risk loci using genetic linkage and chromosomal rearrangements. Nat Genet 39:319-328.

Bailey A, Le Couteur A, Gottesman I, Bolton P, Simonoff E, Yuzda E, Rutter M (1995) Autism as a strongly genetic disorder: evidence from a British twin study. Psychol Med 25:63-77.

Bateup HS, Johnson CA, Denefrio CL, Saulnier JL, Kornacker K, Sabatini BL (2013) Excitatory/inhibitory synaptic imbalance leads to hippocampal hyperexcitability in mouse models of tuberous sclerosis. Neuron 78:510-522.

Bemben MA, Shipman SL, Nicoll RA, Roche KW (2015) The cellular and molecular landscape of neuroligins. Trends Neurosci 38:496-505.

Bena F et al. (2013) Molecular and clinical characterization of 25 individuals with exonic deletions of NRXN1 and comprehensive review of the literature. Am J Med Genet B Neuropsychiatr Genet 162B:388-403.

Berry KP, Nedivi E (2017) Spine Dynamics: Are They All the Same? Neuron 96:43-55.

Boucard AA, Ko J, Sudhof TC (2012) High affinity neurexin binding to cell adhesion G-protein-coupled receptor CIRL1/latrophilin-1 produces an intercellular adhesion complex. J Biol Chem 287:9399-9413.

Bourgeron T (2015) From the genetic architecture to synaptic plasticity in autism spectrum disorder. Nat Rev Neurosci 16:551-563.

Bourne J, Harris KM (2007) Do thin spines learn to be mushroom spines that remember? Curr Opin Neurobiol 17:381-386. 
Chanques G, Ely EW, Garnier O, Perrigault F, Eloi A, Carr J, Rowan CM, Prades A, de Jong A, Moritz-Gasser S, Molinari N, Jaber S (2018) The 2014 updated version of the Confusion Assessment Method for the Intensive Care Unit compared to the 5 th version of the Diagnostic and Statistical Manual of Mental Disorders and other current methods used by intensivists. Ann Intensive Care 8:33.

Chen JA, Penagarikano O, Belgard TG, Swarup V, Geschwind DH (2015) The emerging picture of autism spectrum disorder: genetics and pathology. Annu Rev Pathol 10:111-144.

Chen P, Jing H, Xiong M, Zhang Q, Lin D, Ren D, Wang S, Yin D, Chen Y, Zhou T, Li B, Fei E, Pan BX (2021) Spine impairment in mice high-expressing neuregulin 1 due to LIMK1 activation. Cell Death Dis 12:403.

Chiang MC, Huang AJY, Wintzer ME, Ohshima T, McHugh TJ (2018) A role for CA3 in social recognition memory. Behav Brain Res 354:22-30.

Chubykin AA, Atasoy D, Etherton MR, Brose N, Kavalali ET, Gibson JR, Sudhof TC (2007) Activity-dependent validation of excitatory versus inhibitory synapses by neuroligin-1 versus neuroligin-2. Neuron 54:919-931.

Clement JP, Aceti M, Creson TK, Ozkan ED, Shi Y, Reish NJ, Almonte AG, Miller BH, Wiltgen BJ, Miller CA, Xu X, Rumbaugh G (2012) Pathogenic SYNGAP1 mutations impair cognitive development by disrupting maturation of dendritic spine synapses. Cell 151:709-723.

Comery TA, Harris JB, Willems PJ, Oostra BA, Irwin SA, Weiler IJ, Greenough WT (1997) Abnormal dendritic spines in fragile $\mathrm{X}$ knockout mice: maturation and pruning deficits. Proc Natl Acad Sci U S A 94:5401-5404.

Connor SA, Ammendrup-Johnsen I, Chan AW, Kishimoto Y, Murayama C, Kurihara N, Tada A, Ge Y, Lu H, Yan R, LeDue JM, Matsumoto H, Kiyonari H, Kirino Y, Matsuzaki F, Suzuki T, Murphy TH, Wang YT, Yamamoto T, Craig AM (2016) Altered Cortical Dynamics and Cognitive Function upon Haploinsufficiency of the Autism-Linked Excitatory Synaptic Suppressor MDGA2. Neuron 91:1052-1068.

Courchesne E, Pierce K (2005) Why the frontal cortex in autism might be talking only to itself: local over-connectivity but long-distance disconnection. Curr Opin Neurobiol 15:225-230.

Dalva MB, McClelland AC, Kayser MS (2007) Cell adhesion molecules: signalling functions at the synapse. Nat Rev Neurosci 8:206-220.

De Rubeis S et al. (2014) Synaptic, transcriptional and chromatin genes disrupted in autism. Nature 515:209-215.

Dong Z, Chen W, Chen C, Wang H, Cui W, Tan Z, Robinson H, Gao N, Luo B, Zhang L, Zhao K, Xiong WC, Mei L (2020) CUL3 Deficiency Causes Social Deficits and Anxiety-like Behaviors by Impairing Excitation-Inhibition Balance through the Promotion of Cap-Dependent Translation. Neuron 105:475-490 e476.

Etherton MR, Blaiss CA, Powell CM, Sudhof TC (2009) Mouse neurexin-1alpha deletion causes correlated electrophysiological and behavioral changes consistent with cognitive impairments. Proc Natl Acad Sci U S A 106:17998-18003.

Farhy-Tselnicker I, Allen NJ (2018) Astrocytes, neurons, synapses: a tripartite view on cortical circuit development. Neural Dev 13:7.

Feldman DE (2009) Synaptic mechanisms for plasticity in neocortex. Annu Rev Neurosci 32:33-55.

Feldman DE, Brecht M (2005) Map plasticity in somatosensory cortex. Science 310:810-815.

Foldy C, Darmanis S, Aoto J, Malenka RC, Quake SR, Sudhof TC (2016) Single-cell RNAseq reveals cell adhesion molecule profiles in electrophysiologically defined neurons. Proc Natl Acad Sci U S A 
113:E5222-5231.

Forrest MP, Parnell E, Penzes P (2018) Dendritic structural plasticity and neuropsychiatric disease. Nat Rev Neurosci 19:215-234.

Fuerst PG, Koizumi A, Masland RH, Burgess RW (2008) Neurite arborization and mosaic spacing in the mouse retina require DSCAM. Nature 451:470-474.

Fuerst PG, Bruce F, Tian M, Wei W, Elstrott J, Feller MB, Erskine L, Singer JH, Burgess RW (2009) DSCAM and DSCAML1 function in self-avoidance in multiple cell types in the developing mouse retina. Neuron 64:484-497.

Harris KM, Jensen FE, Tsao B (1992) Three-dimensional structure of dendritic spines and synapses in rat hippocampus (CA1) at postnatal day 15 and adult ages: implications for the maturation of synaptic physiology and long-term potentiation. J Neurosci 12:2685-2705.

Hattori D, Millard SS, Wojtowicz WM, Zipursky SL (2008) Dscam-mediated cell recognition regulates neural circuit formation. Annu Rev Cell Dev Biol 24:597-620.

Holtmaat A, Svoboda K (2009) Experience-dependent structural synaptic plasticity in the mammalian brain. Nat Rev Neurosci 10:647-658.

Hughes ME, Bortnick R, Tsubouchi A, Baumer P, Kondo M, Uemura T, Schmucker D (2007) Homophilic Dscam interactions control complex dendrite morphogenesis. Neuron 54:417-427.

Huguet G, Ey E, Bourgeron T (2013) The genetic landscapes of autism spectrum disorders. Annu Rev Genomics Hum Genet 14:191-213.

Huguet G, Benabou M, Bourgeron T (2016) The Genetics of Autism Spectrum Disorders. In: A Time for Metabolism and Hormones (Sassone-Corsi P, Christen Y, eds), pp 101-129. Cham (CH).

Hutsler JJ, Zhang H (2010) Increased dendritic spine densities on cortical projection neurons in autism spectrum disorders. Brain Res 1309:83-94.

Iossifov I et al. (2014) The contribution of de novo coding mutations to autism spectrum disorder. Nature 515:216-221.

Irwin SA, Galvez R, Greenough WT (2000) Dendritic spine structural anomalies in fragile-X mental retardation syndrome. Cereb Cortex 10:1038-1044.

Jia YL, Jing LJ, Li JY, Lu JJ, Han R, Wang SY, Peng T, Jia YJ (2011) Expression and significance of DSCAM in the cerebral cortex of APP transgenic mice. Neurosci Lett 491:153-157.

Jiang YH, Ehlers MD (2013) Modeling autism by SHANK gene mutations in mice. Neuron 78:8-27.

Kim JH, Wang X, Coolon R, Ye B (2013) Dscam expression levels determine presynaptic arbor sizes in Drosophila sensory neurons. Neuron 78:827-838.

Laflamme OD, Lemieux M, Thiry L, Bretzner F (2019) DSCAM Mutation Impairs Motor Cortex Network Dynamic and Voluntary Motor Functions. Cereb Cortex 29:2313-2330.

Lemieux M, Laflamme OD, Thiry L, Boulanger-Piette A, Frenette J, Bretzner F (2016) Motor hypertonia and lack of locomotor coordination in mutant mice lacking DSCAM. J Neurophysiol 115:1355-1371.

Li HL, Huang BS, Vishwasrao H, Sutedja N, Chen W, Jin I, Hawkins RD, Bailey CH, Kandel ER (2009) Dscam mediates remodeling of glutamate receptors in Aplysia during de novo and learning-related synapse formation. Neuron 61:527-540.

Li MY, Miao WY, Wu QZ, He SJ, Yan G, Yang Y, Liu JJ, Taketo MM, Yu X (2017) A Critical Role of Presynaptic Cadherin/Catenin/p140Cap Complexes in Stabilizing Spines and Functional Synapses in the Neocortex. Neuron 94:1155-1172 e1158.

Ly A, Nikolaev A, Suresh G, Zheng Y, Tessier-Lavigne M, Stein E (2008) DSCAM is a netrin receptor that 
collaborates with DCC in mediating turning responses to netrin-1. Cell 133:1241-1254.

Matthews BJ, Kim ME, Flanagan JJ, Hattori D, Clemens JC, Zipursky SL, Grueber WB (2007) Dendrite self-avoidance is controlled by Dscam. Cell 129:593-604.

Maynard KR, Stein E (2012) DSCAM contributes to dendrite arborization and spine formation in the developing cerebral cortex. The Journal of neuroscience : the official journal of the Society for Neuroscience 32:16637-16650.

Millard SS, Lu Z, Zipursky SL, Meinertzhagen IA (2010) Drosophila dscam proteins regulate postsynaptic specificity at multiple-contact synapses. Neuron 67:761-768.

Moy SS, Nadler JJ, Perez A, Barbaro RP, Johns JM, Magnuson TR, Piven J, Crawley JN (2004) Sociability and preference for social novelty in five inbred strains: an approach to assess autistic-like behavior in mice. Genes Brain Behav 3:287-302.

Nakanishi M, Nomura J, Ji X, Tamada K, Arai T, Takahashi E, Bucan M, Takumi T (2017) Functional significance of rare neuroligin 1 variants found in autism. PLoS Genet 13:e1006940.

Nelson SB, Valakh V (2015) Excitatory/Inhibitory Balance and Circuit Homeostasis in Autism Spectrum Disorders. Neuron 87:684-698.

Petersen CC, Crochet S (2013) Synaptic computation and sensory processing in neocortical layer 2/3. Neuron 78:28-48.

Ronemus M, Iossifov I, Levy D, Wigler M (2014) The role of de novo mutations in the genetics of autism spectrum disorders. Nat Rev Genet 15:133-141.

Rosenberg RE, Law JK, Yenokyan G, McGready J, Kaufmann WE, Law PA (2009) Characteristics and concordance of autism spectrum disorders among 277 twin pairs. Arch Pediatr Adolesc Med 163:907-914.

Rosenfeld CS, Ferguson SA (2014) Barnes maze testing strategies with small and large rodent models. J Vis Exp:e51194.

Rubenstein JL, Merzenich MM (2003) Model of autism: increased ratio of excitation/inhibition in key neural systems. Genes Brain Behav 2:255-267.

Sacco R, Militerni R, Frolli A, Bravaccio C, Gritti A, Elia M, Curatolo P, Manzi B, Trillo S, Lenti C, Saccani M, Schneider C, Melmed R, Reichelt KL, Pascucci T, Puglisi-Allegra S, Persico AM (2007) Clinical, morphological, and biochemical correlates of head circumference in autism. Biol Psychiatry 62:1038-1047.

Sachse SM, Lievens S, Ribeiro LF, Dascenco D, Masschaele D, Horre K, Misbaer A, Vanderroost N, De Smet AS, Salta E, Erfurth ML, Kise Y, Nebel S, Van Delm W, Plaisance S, Tavernier J, De Strooper B, De Wit J, Schmucker D (2019) Nuclear import of the DSCAM-cytoplasmic domain drives signaling capable of inhibiting synapse formation. EMBO J 38.

Saito Y, Oka A, Mizuguchi M, Motonaga K, Mori Y, Becker LE, Arima K, Miyauchi J, Takashima S (2000) The developmental and aging changes of Down's syndrome cell adhesion molecule expression in normal and Down's syndrome brains. Acta Neuropathol 100:654-664.

Satterstrom FK et al. (2020) Large-Scale Exome Sequencing Study Implicates Both Developmental and Functional Changes in the Neurobiology of Autism. Cell 180:568-584 e523.

Schmucker D, Clemens JC, Shu H, Worby CA, Xiao J, Muda M, Dixon JE, Zipursky SL (2000) Drosophila Dscam is an axon guidance receptor exhibiting extraordinary molecular diversity. Cell 101:671-684.

Shen L, Xiao Z, Pan Y, Fang M, Li C, Chen D, Wang L, Xi Z, Xiao F, Wang X (2011) Altered expression of Dscam in temporal lobe tissue from human and experimental animals. Synapse 65:975-982. 
1013

Sterne GR, Kim JH, Ye B (2015) Dysregulated Dscam levels act through Abelson tyrosine kinase to enlarge presynaptic arbors. Elife 4.

Stessman HA et al. (2017) Targeted sequencing identifies 91 neurodevelopmental-disorder risk genes with autism and developmental-disability biases. Nat Genet 49:515-526.

Sudhof TC (2008) Neuroligins and neurexins link synaptic function to cognitive disease. Nature 455:903-911.

Sudhof TC (2017) Synaptic Neurexin Complexes: A Molecular Code for the Logic of Neural Circuits. Cell 171:745-769.

Tabuchi K, Blundell J, Etherton MR, Hammer RE, Liu X, Powell CM, Sudhof TC (2007) A neuroligin-3 mutation implicated in autism increases inhibitory synaptic transmission in mice. Science 318:71-76.

Thiry L, Lemieux M, O DL, Bretzner F (2016) Role of DSCAM in the development of the spinal locomotor and sensorimotor circuits. J Neurophysiol 115:1338-1354.

Varoqueaux F, Aramuni G, Rawson RL, Mohrmann R, Missler M, Gottmann K, Zhang W, Sudhof TC, Brose N (2006) Neuroligins determine synapse maturation and function. Neuron 51:741-754.

Wang T et al. (2016) De novo genic mutations among a Chinese autism spectrum disorder cohort. Nat Commun 7:13316.

Wang YN, Figueiredo D, Sun XD, Dong ZQ, Chen WB, Cui WP, Liu F, Wang HS, Li HW, Robinson H, Fei EK, Pan BX, Li BM, Xiong WC, Mei L (2018) Controlling of glutamate release by neuregulin3 via inhibiting the assembly of the SNARE complex. Proc Natl Acad Sci U S A 115:2508-2513.

Xu Y, Ye H, Shen Y, Xu Q, Zhu L, Liu J, Wu JY (2011) Dscam mutation leads to hydrocephalus and decreased motor function. Protein Cell 2:647-655.

Yamagata M, Sanes JR (2008) Dscam and Sidekick proteins direct lamina-specific synaptic connections in vertebrate retina. Nature 451:465-469.

Yamakawa K, Huot YK, Haendelt MA, Hubert R, Chen XN, Lyons GE, Korenberg JR (1998) DSCAM: a novel member of the immunoglobulin superfamily maps in a Down syndrome region and is involved in the development of the nervous system. Hum Mol Genet 7:227-237.

Yang Y, Cheng Z, Tang H, Jiao H, Sun X, Cui Q Luo F, Pan H, Ma C, Li B (2017) Neonatal Maternal Separation Impairs Prefrontal Cortical Myelination and Cognitive Functions in Rats Through Activation of Wnt Signaling. Cereb Cortex 27:2871-2884.

Yizhar O, Fenno LE, Prigge M, Schneider F, Davidson TJ, O'Shea DJ, Sohal VS, Goshen I, Finkelstein J, Paz JT, Stehfest K, Fudim R, Ramakrishnan C, Huguenard JR, Hegemann P, Deisseroth K (2011) Neocortical excitation/inhibition balance in information processing and social dysfunction. Nature 477:171-178.

Yuen RK et al. (2017) Whole genome sequencing resource identifies 18 new candidate genes for autism spectrum disorder. Nat Neurosci 20:602-611.

Yuste R (2013) Electrical compartmentalization in dendritic spines. Annu Rev Neurosci 36:429-449.

Yuste R, Bonhoeffer T (2004) Genesis of dendritic spines: insights from ultrastructural and imaging studies. Nat Rev Neurosci 5:24-34.

Zhang Y, Bonnan A, Bony G, Ferezou I, Pietropaolo S, Ginger M, Sans N, Rossier J, Oostra B, LeMasson G, Frick A (2014) Dendritic channelopathies contribute to neocortical and sensory hyperexcitability in Fmr1(-/y) mice. Nat Neurosci 17:1701-1709.

Zhuo L, Theis M, Alvarez-Maya I, Brenner M, Willecke K, Messing A (2001) hGFAP-cre transgenic mice for manipulation of glial and neuronal function in vivo. Genesis 31:85-94. 


\section{Figure legends}

1058 Fig 1. Downregulated expression of DSCAM during synapse maturation.

1059 A-B The mRNA levels of selected CAMs during postnatal synapse development. WT 1060 mice cortex was isolated from P0 to P60 for mRNA extraction and qRT-PCR analysis 1061

(A). Hot map analysis of qRT-PCR results for selected CAMs (B). $\mathrm{N}=3$ mice for each age. C-D DSCAM protein level in cortical neurons from DIV3 to DIV21. Primary cortical neurons were lysed at indicated DIV for western blotting (WB) (C). Quantitative analysis of relative protein levels in C, the relative protein levels of all three proteins were set to "1" (D). Data were from three independent experiments and shown as mean \pm SEM. E-F DSCAM expression during brain development. Whole-brain homogenates from WT mice at different (indicated) stages from E12.5 to P60 were subjected to WB with the anti-DSCAM antibody (E). Quantitative analysis of data in $\mathbf{E}(\mathbf{F}) . \mathbf{N}=3$ mice for each age. $\mathbf{G}$ Distribution of DSCAM in PSD fraction. Subcellular fractions of the WT brains were blotted with anti-DSCAM, anti-PSD-95 (a PSD marker) and anti-synaptophysin (a presynaptic marker). S1, supernatant 1; P1, pelleted nuclear fraction; S2, supernatant 2; P2, washed crude synaptosomal fraction; S3, crude synaptic vesicle fraction; SV, synaptic vesicle fraction; P3, lysed synaptosomal membrane fraction; SPM, synaptosomal membrane fraction; Pre, presynaptic fraction. H-K Distribution of DSCAM in neurons. Representative images of DSCAM-His distribution in dendrites $(\mathbf{H})$ and in PSD (K). Cortical neurons were isolated from P0 pups, cotransfected with DSCAM-His and GFP at DIV9 and fixed for 
1078

1079

1080

1081

1082

1083

1084

1085

1086

1087

1088

1089

1090

1091

1092

1093

1094

1095

1096

1097

1098

1099

staining with anti-His and anti-PSD-95 antibodies at DIV17. In H: arrow, mature (M) dendritic spine; arrowhead, immature spine (IM) dendritic spine. Scale bar, $32 \mu \mathrm{m}$ (upper panel) and $10 \mu \mathrm{m}$ (lower panel). Quantitative analysis of DSCAM-His fluorescence intensity (I) and puncta size (J) in $\mathbf{H} . \mathbf{N}=11$ neurons, ${ }^{*} \mathrm{p}<0.05,{ }^{* *} \mathrm{p}<$ 0.01 , and ${ }^{* *} \mathrm{p}<0.001$; one-way ANOVA. In $\mathrm{K}$, arrowheads indicate DSCAM-His that was colocalized with PSD-95.

\section{Fig. 2 Normal gross brain structure of GFAP-DSCAM f/f.}

A The genomic structure of floxed DSCAM mice. The first loxp (1st loxP) was inserted between exon1 and exon2, and the second loxp (2nd loxP) was inserted after the last exon (exon33). B Genotyping of wild type (wt, m1), GFAP-DSCAM f/wt (m2) and GFAP-DSCAM f/f (m3) mice. Primer pair 1 (PP1) and PP2 were for 1st loxP, PP3 and PP4 were for 2nd loxP, PP5 was for wt allele and PP6 for GFAP-Cre transgene. C DSCAM expression is decreased in the brain of GFAP-DSCAM $\mathrm{f} / \mathrm{f}$ mice. Whole brain lysates from GFAP-DSCAM f/f and control mice were probed with anti-DSCAM antibody. Actin served as a loading control. The relative DSCAM level (band intensity of DSCAM / actin) was quantified. $N=4$ mice for control, $n=5$ mice for GFAP-DSCAM f/f mice. ${ }^{* \star *} \mathrm{p}<0.001$, Student's t-test. Data were shown as mean \pm SEM. D-F GFAP-DSCAM f/f mice displayed normal body weight and gross brain structure, but increased brain weight. Representative appearance and brain images of GFAP-DSCAM f/f and control mice (D). Quantitative analysis of body and brain weight for each genotype (E). Brain weight: $n=5$ for control, $n=6$ for GFAP-DSCAM f/f mice. 
1100

1101

1102

1103

1104

1105

1106

1107

1108

1109

1110

1111

1112

1113

1114

1115

1116

1117

1118

1119

1120

1121

Data were shown as mean $\pm \mathrm{SEM}$; ${ }^{*} \mathrm{p}<0.05$, ns, $\mathrm{p}>0.05$ (student's t-test). Representative Nissle-staining images of brains from each genotype. Scale bar, 1 mm (F). G-I GFAP-DSCAM f/f mice displayed normal densities of NeuN+ and PV+ neurons. Representative NeuN immunostaining images and quantitative analysis of $\mathrm{NeuN}+$ cell densities in sensory cortex $(\mathbf{G})$ and hippocampus $(\mathbf{H})$ of each genotype. Scale bar, $100 \mu \mathrm{m}$ in $\mathbf{G}$ and $32 \mu \mathrm{m}$ in $\mathbf{H} . \mathrm{N}=32$ slices from 4 control mice, $\mathrm{n}=43$ slices from 5 GFAP-DSCAM f/f mice. Data were shown as mean \pm SEM. $n s, p>0.05$, Student's t-test. Representative PV immunostaining images and quantitative analysis of PV+ cell densities in the sensory cortex of each genotype (I). Scale bar, $100 \mu \mathrm{m} . \mathrm{N}$ $=17$ slices from 4 control mice, $n=21$ slices from 5 GFAP-DSCAM f/f mice. Data were shown as mean \pm SEM. ns, $p>0.05$, Student's t-test.

Fig 3. Abnormal spine maturation in sensory cortex of GFAP-DSCAM f/f mice.

A-R GFAP-DSCAM f/f mice displayed increased spine maturation in the sensory cortex (A-E and J-N) and increased dendritic arborization at P21 (F-I and O-R). Representative Golgi staining images of dendritic spines in sensory cortex from P12, P21 and P42 male mice of each genotype (A and J). Scale bar, $10 \mu \mathrm{m}$. Quantitative analysis of total (B and $\mathbf{K}), \mathbf{M}(\mathbf{C}$ and $\mathbf{L})$ and IM ( $\mathbf{D}$ and $\mathbf{M})$ spine density, as well as spine head width ( $E$ and $\mathbf{N}$ ). Representative dendrite trace images from Golgi staining in sensory cortex L2/3 (F) and L5 (O) of each genotype at P12, P21 and P42. Scale bars, $32 \mu \mathrm{m}$. Quantitative analysis of dendritic length ( $\mathbf{G}$ and $\mathbf{P}$ ), branches ( $\mathbf{H}$ and $\mathbf{Q}$ ), and complexity $(\mathbf{I}$ and $\mathbf{R}$ ) in $\mathbf{F}$ and $\mathbf{O} . \mathbf{N}=5$ mice for each genotype. Data were shown 
1122 1123 ANOVA.

1124

1125 as mean \pm SEM. Ns, $p>0.05,{ }^{*} p<0.05$, ** $p<0.01$, and ${ }^{* * *} p<0.001$; two-way

\section{Fig. 4 Increased asymmetric synapse number and PSD size in sensory cortex of}

\section{GFAP-DSCAM f/f mice}

A-F GFAP-DSCAM f/f mice displayed increased density of asymmetric (AS) synapses and enlarged PSD area. Representative electron microscopy images of sensory cortex L2/3 from each genotype (A). For each genotype, scale bar was $1 \mu \mathrm{m}$ for left panels and $0.5 \mu \mathrm{m}$ for right enlarged insets. Red arrowheads, AS synapses; black arrowheads, symmetric (SY) synapses. Red box, enlarged insets of AS synapses; black box, enlarged insets of SY synapses. B-F Quantitative analysis of data in A. N = 3 for each genotype. Data were shown as mean \pm SEM. ** $p<0.01$, *** $p<0.001$, Student's t-test, two-way ANOVA.

Fig 5. Increased glutamatergic transmission in sensory cortex L2/3 of GFAP-DSCAM f/f mice.

A-F GFAP-DSCAM f/f mice displayed increased mEPSC frequency, but normal mIPSC. The sensory cortical slices of each genotype at P12 (A and D), P21 (D and E) and P42 (C and F) were collected for whole-cell voltage clamp recording of mEPSC (A-C) and mIPSC (D-F). Upper panels, representative traces of mEPSCs (A-C) and mIPSC (D-F). Scale bars, 30 pA, 1 s. Lower panels, histogram summary and cumulative probability plots of mEPSC (A-C) and mIPSC (D-F) inter-event intervals 
1144

1145

1146

1147

1148

1149

1150

1151

1152

1153

1154

1155

1156

1157

1158

1159

1160

1161

1162

1163

1164

1165

and amplitude. P12: $n=34$ neurons from 4 control, $n=16$ neurons from 5 GFAP-DSCAM f/f mice; P21: $n=20$ neurons from 5 control, $n=22$ neurons from 5 GFAP-DSCAM f/f mice. P42: $\mathrm{n}=17$ neurons from 4 control, $\mathrm{n}=17$ neuron from 4 GFAP-DSCAM f/fmice. Data were shown as mean \pm SEM. ${ }^{* \star} p<0.01,{ }^{* \star *} p<0.001$, Student's t-test.

Fig 6. Increased spine maturation and stability in DSCAM knockdown neurons. A Knockdown of overexpressed mouse DSCAM-His in HEK293T cells. HEK293T cells were cotransfected with mouse DSCAM-His, small hairpin RNA (sh-RNA) for mouse/rat DSCAM (sh-DSCAM) or control scramble sh-RNA (sh-control), and human DSCAM. 24hr after transfection, cells were lysed and subjected to WB with anti-DSCAM antibody. Data were from three independent experiments and are shown as mean \pm SEM. Ns, $p>0.05,{ }^{* \star *} p<0.001$; Student's t-test. B-C Knockdown of DSCAM in cultured cortical neurons increased mature spine density. Representative images of pyramidal neuron morphology and spine density in cortical neurons (B). Neurons were isolated from E18 rat to culture and transfected with GFP plus sh-DSCAM or sh-control and hDSCAM or not at DIV9, and they were fixed for staining at DIV17. Scale bar, $16 \mu \mathrm{m}$ (upper panel) and $10 \mu \mathrm{m}$ (lower panel). Statistical analysis of total spine density in B (C). $N=29$ neurons for sh-control, $n=79$ neurons for sh-DSCAM, $\mathrm{n}=22$ neurons for shDSCAM + hDSCAM. Ns, $\mathrm{p}>0.05,{ }^{* * *} \mathrm{p}<0.001$ student's t-test. Data were shown as mean \pm SEM. D-F Knockdown of DSCAM in cultured cortical neurons increased the density and size of PSD-95 puncta. 
1166

Representative images of PSD-95 staining in cortical neurons (D). Primary cortical neurons were transfected with sh-DSCAM or sh-control plus GFP at DIV9, and they were fixed for PSD-95 staining at DIV17. Dotted line box, dendrite of transfected neurons (enlarge in middle panels); Solid line box, dendrite of non-transfected neurons (enlarge in lower panels). Scale bar, $16 \mu \mathrm{m}$ (upper panel) and $10 \mu \mathrm{m}$ (lower two panels). Quantitative analysis of data in D for the density (E) and size (F) of PSD-95 puncta. $N=21$ neurons for transfected and non-transfected respectively in sh-control, $\mathrm{n}=49$ neurons for transfected and non-transfected respectively in sh-DSCAM. ${ }^{* *} p<0.01,{ }^{* * *} p<0.001$, two-way ANOVA. Data were shown as mean \pm SEM. G Representative images of time-lapse imaging from cortical neurons transfected with sh-DSCAM or sh-control taken at 5 adjacent time points during the 60-min live-imaging period. Scale bar, $10 \mu \mathrm{m} . \mathrm{N}=21$ neurons for sh-control, $\mathrm{n}=19$ neurons for sh-DSCAM. H-J Quantitative analysis for percentages of stable (H), new (I) and eliminated spines (J). Ns, $p>0.05,{ }^{* *} p<0.01,{ }^{* *} p<0.001$, student's t-test. Data were shown as mean \pm SEM. K-M Linear correlation of spine density and percentage of stable (K), new (L) or eliminated (M) spines in DSCAM knockdown neurons. $R=0.7595$ for stable spines, $R=-0.4751$ for new spines and $R=-0.6434$ for eliminated spines.

\section{Fig. 7 Interaction of DSCAM to NLGN1 through its ECD.}

A-B DSCAM interacts with NLGNs. HEK293T cells were cotransfected with DSCAM-His and indicated constructs for co-IP assays with anti-His (A) or anti-GFP 
1188 1189 1190 1191 1192 1193 1194 1195 1196 1197 1198 1199 1200 antibody (B). The inputs and resulting co-IP complexes were blotted with anti-GFP and anti-His antibodies. C DSCAM-ECD interacts with NLGNs. HEK293T cells were cotransfected with FLAG-tagged ECD of DSCAM (FLAG-ECD) or empty control (Mock) and indicated constructs for co-IP assay with anti-GFP antibody. FLAG-ECD was secreted to the medium. HEK293T cells were transfected with FLAG-ECD or empty control. After $24 \mathrm{~h}$, the medium was changed to conditional medium (CM) containing $0.5 \%$ fetal bovine serum for another $24 \mathrm{~h}$. The CM was collected to IP with anti-FLAG antibody to enrich secretable FLAG-ECD. The resulting IP complexes and cell lysates were probed with anti-FLAG antibody. E-F FLAG-ECD binds to the cell surface of cells expressing NLGNs. HEK293T cells were cotransfected with NLGN1-4 or empty vector plus GFP for $24 \mathrm{~h}$ and fixed. Before the immunostaining with anti-FLAG antibody, the fixed cells were incubated with CM containing FLAG-ECD for $4 \mathrm{~h}$. Representative immunostaining images of cells treated with FLAG-ECD (E). Scale bar, $8 \mu \mathrm{m}$. Quantitative analysis of relative red fluorescence intensity (intensity of red fluorescence / green fluorescence) in E (F). Data were from three independent experiments and shown as mean \pm SEM. ${ }^{* \star} p<$ 0.001, one-way ANOVA. G Endogenous DSCAM interacts with NLGN1 in vivo. WT brain lysates were IPed with anti-DSCAM antibody and resulting complexes were blotted with anti-DSCAM and anti-NLGN1 antibodies. H-I NLGN1 protein level was not altered in the GFAP-DSCAM f/f mice. Whole-brain homogenates from GFAP-DSCAM f/f and control mice were subjected to WB with indicated antibodies (H). Quantitative analysis of data in $\mathbf{H}(\mathbf{I}) . \mathbf{N}=3$ mice for each genotype. Data were 
1210

1211

1212

1213

1214

1215

1216

1217

1218

1219

1220

1221

1222

1223

1224

1225

1226

1227

1228

1229

1230

1231

shown as mean \pm SEM. ${ }^{\star \star \star} p<0.001$, two-way ANOVA. J-K NLGN1 protein level was increased in SPM fraction of GFAP-DSCAM f/f mice. SPM fractions from each genotype were probed with anti-DSCAM and anti-NLGN1 antibodies (J). Quantitative analysis of data in $\mathbf{J}(\mathbf{K}) . \mathbf{N}=9$ mice for each genotype. Data were shown as mean \pm SEM. ${ }^{* *} \mathrm{p}<0.01,{ }^{* * *} \mathrm{p}<0.001$, two-way ANOVA.

\section{Fig 8. Inhibition of NLGN1-NRXN1 $\beta$ interaction by DSCAM.}

A-B DSCAM inhibits the NLGN1-NRXN1 $\beta$ interaction. HEK293T cells were cotransfected with different amounts of DSCAM-His and indicated constructs. Cell Iysates were IPed with anti-FLAG antibody and resulting complexes were blotted with anti-GFP, anti-FLAG and anti-His antibodies (A). The relative intensity of co-IPed NRXN1 $\beta$ (intensity of co-IPed NRXN1 / IPed NLGN1) was quantified in B. Data were from three independent experiments and shown as mean \pm SEM. ${ }^{*} p<0.05,{ }^{* *} p<$ 0.01, one-way ANOVA. C-G DSCAM inhibits transcellular NLGN1-NRXN1ß interaction in cell surface binding assay (C-D) and cell aggregation assay (E-G). COS-7 cells were cotransfected with NLGN1 and increasing amounts of DSCAM-His for $24 \mathrm{~h}$ and incubated with purified NRXN1ß-ECD-myc for $1 \mathrm{~h}$ before fixation. Fixed cells were immuno-stained with anti-NLGN1, anti-myc and anti-His antibodies. Representative immunostaining images of cells (C). Scale bar, $10 \mu \mathrm{m}$. Quantitative analysis of relative red fluorescence intensity (intensity of red fluorescence / green fluorescence) in C (D). Data were from three independent experiments and shown as mean \pm SEM. ${ }^{* *} p<0.01,{ }^{* *} p<0.001$, one-way ANOVA. Schematic illustration of cell 
aggregation assay (E). HEK293T cells expressing NRXN1ß or empty vector with RFP (red cells) were mixed with cells expressing NLGN1 and GFP plus different amounts of DSCAM (green cells). After $1 \mathrm{~h}$, cell mixtures were imaged (F) and cell aggregates were counted (G). Scale bar, $200 \mu \mathrm{m} . \mathrm{N}=15$ images for each condition from three independent experiments. Data were shown as mean \pm SEM. ${ }^{*}$ p $<0.01$, *** $\mathrm{p}<$ 0.001, one-way ANOVA. H-I DSCAM-ECD disrupts transcellular NLGN1-NRXN1ß interaction. Different amounts of CM with FLAG-ECD were added into HEK293T cell mixtures of NRXN1ß (red cells) and NLGN1 (green cells). Cell aggregates were imaged $(\mathbf{H})$ and counted (I). Scale bar, $200 \mu \mathrm{m}$. Data were from three independent experiments and shown as mean \pm SEM. ** $p<0.01$, and ${ }^{* * *} p<0.001$, one-way ANOVA. J-K DSCAM-ECD rescued spine over-maturation in DSCAM knockdown neurons. Primary cortical neurons were transfected at DIV9 with sh-DSCAM or sh-control. At DIV15, transfected neurons were incubated with CM containing FLAG-ECD or mock for 2 days and fixed. Representative images of dendritic spines (J). Scale bar, $10 \mu \mathrm{m}$. Quantitative analysis of total spine density in $\mathbf{J}(\mathbf{K}) . \mathbf{N}=20$ neurons for sh-control + mock; $n=48$ neurons for sh-DSCAM + mock; $n=21$ neurons for sh-DSCAM + FLAG-ECD. Data were shown as mean \pm SEM. ${ }^{* *} p<0.01$, and ${ }^{* * *} p$ $<0.001$, one-way ANOVA.

Fig 9. Autism-like behaviors and enhanced spatial memory in GFAP-DSCAM f/f mice. A-B GFAP-DSCAM f/f mice displayed increased circling and grooming in OFT. During 
10-min OFT, mice circling numbers (A) and grooming time (B) were counted. For circling, $n=14$ for control mice, $n=15$ for GFAP-DSCAM f/f mice; for grooming, $n=$ 16 for control mice, $\mathrm{n}=19$ for GFAP-DSCAM f/f mice. Data were shown as mean \pm SEM. ** $\mathrm{p}<0.01$, Student's t-test. C-I GFAP-DSCAM f/f mice displayed reduced social novelty. Representative heat map for the mice movements in three-chamber social interaction test (C). S1, stranger1 mouse; S2, stranger2 mouse; E, empty cage; C, center chamber. Quantitative analysis of time staying in each chamber (D and G), interaction time $(\mathbf{E}$ and $\mathbf{H})$, and social interaction index (F and $\mathbf{I})$. Social interaction index was calculated as: in F, [interaction time (S1) - interaction time (E)] / [interaction time (S1) + interaction time (E)] for each genotype; in I, [interaction time (S2) interaction time (S1)] / [interaction time (S2) + interaction time (S1)] for each genotype. $\mathrm{N}=17$ mice for control, $\mathrm{n}=19$ for GFAP-DSCAM f/f mice. Data were shown as mean \pm SEM. Ns, $p>0.05 ;{ }^{* \star *} p<0.001$. Student's t-test for F and I, two-way ANOVA for D, E, G and H. J-K GFAP-DSCAM f/f mice displayed elevated spatial memory in Barnes maze. Quantitative analysis of escape latency $(\mathbf{J})$ and error numbers $(\mathbf{K})$ in a 4-day training session. Quantitative analysis of moved distances (L), latency to target (M), time in target $(\mathbf{N})$ and correct pokes $(\mathbf{O})$ in the test session. $\mathrm{N}=14$ for control mice, $\mathrm{n}$ = 20 for GFAP-DSCAM f/f mice. Data were shown as mean \pm SEM. Ns, $p>0.05 ;{ }^{*}<$ 0.05; ** $p<0.01$. Student's t-test for L-O, two-way ANOVA for J-K. P-S GFAP-DSCAM f/f mice displayed anxiety-like behavior in OFT. Male 2-month mice were placed in the chambers and movement was monitored for $10 \mathrm{~min}$. Representative traces of mice in OFT $(\mathbf{P})$. The square with a dotted line indicates the 
1276

1277

1278

1279

1280

1281

1282

1283

1284

1285

1286

1287

1288

1289

1290

1291

1292

1293

1294

1295

1296

1297

center area. Quantitative analysis of traveled distance (Q), duration in the center (R) and velocity (S). $\mathrm{N}=19$ for control mice, $\mathrm{n}=21$ for GFAP-DSCAM f/f mice. Data were shown as mean \pm SEM. ${ }^{* *} p<0.01$, Student's t-test for $\mathbf{R}$ and $\mathbf{S}$, Mann-Whitney $\mathrm{U}$ test for Q. T-W GFAP-DSCAM f/f mice displayed anxiety-like behavior in EPM. Mice were put in the center of the EPM and they could freely explore for $10 \mathrm{~min}$. The time stayed in and entries into the open arms were recorded. Representative traces of mice in EPM (T). Quantitative analysis of entries into the open arms $(\mathbf{U})$ and the closed arms (V), as well as duration in the open arms (W). N = 15 for control mice, $\mathrm{n}=17$ for GFAP-DSCAM f/f mice. Data were shown as mean \pm SEM. * $p<0.05$, student's t-test.

\section{Fig. 10 Spine overmaturation in NEX-DSCAM f/f mice.}

A DSCAM is expressed in neurons. Whole brain lysates, as well as cell lysates of cultured neurons and astrocytes from mice were probed with anti-DSCAM antibody. B-C DSCAM expression is reduced in NEX-DSCAM $\mathrm{f} / \mathrm{f}$ mice. Lysates of isolated sensory cortex from each genotype were probed with anti-DSCAM antibody (B). Quantitative analysis of relative DSCAM intensity in B (C). N = 3 mice for each genotype. Data were shown as mean \pm SEM. ${ }^{* \star} p<0.01$, student's test. D-H NEX-DSCAM f/f mice displayed increased spine maturation in the sensory cortex L2/3. Representative Golgi staining images of dendritic spines in sensory cortex (D). Scale bar, $10 \mu \mathrm{m}$. Quantitative analysis of total I, M (F) and IM (G) spine density, as well as spine head width $(\mathrm{H}) . \mathrm{N}=3$ mice for each genotype. Data were shown as mean \pm SEM. ${ }^{*} p<0.05,{ }^{* *} p<0.01$, and ${ }^{* * *} p<0.001$, Student's t-test. I-L NEX-DSCAM f/f 
1298

1299

1300

1301

1302

1303

1304

1305

1306

1307

1308

1309

1310

1311

1312

1313

1314

1315

1316

1317

1318

1319

mice displayed normal in OFT. Representative traces of mice in OFT (I). Quantitative analysis of traveled distances $(\mathbf{J})$, duration in the center $(\mathbf{K})$ and velocity $(\mathbf{L}) . \mathbf{N}=11$ for control mice, $\mathrm{n}=11$ for NEX-DSCAM f/f mice. Data were shown as mean $\pm \mathrm{SEM}$. Ns, $p>0.05 ;{ }^{* *} p<0.01$. Student's t-test for $\mathbf{K}$ and $\mathbf{L}$, Mann-Whitney $\mathbf{U}$ test for $\mathbf{J} . \mathbf{M}-\mathbf{P}$ NEX-DSCAM f/f mice displayed normal in EPM. Representative traces of mice in EPM (M). Quantitative analysis of entries into the open arms $(\mathbf{N})$ and the closed arms (O), as well as duration in the open arms $(\mathbf{P}) . \mathrm{N}=13$ for control mice, $\mathrm{n}=10$ for NEX-DSCAM f/f mice. Data were shown as mean \pm SEM. Ns, $p>0.05 ;{ }^{* *} p<0.01$. Student's t-test.

\section{Fig 11. Autism-like behaviors and enhanced spatial memory in NEX-DSCAM f/f} mice.

A-B NEX-DSCAM f/f mice displayed increased circling and grooming in OFT. During 10-min OFT, mice circling numbers $(\mathbf{A})$ and grooming time $(\mathbf{B})$ were counted. $\mathrm{N}=11$ for control mice, $\mathrm{n}=11$ for NEX-DSCAM f/f mice. Data were shown as mean \pm SEM. * $\mathrm{p}<0.05$, Student's t-test. C-I NEX-DSCAM f/f mice displayed reduced social novelty. Representative heat map for the mice movements in three-chamber social interaction test (C). Quantitative analysis of time staying in each chamber (D and $\mathbf{G}$ ), interaction time $(\mathbf{E}$ and $\mathbf{H})$, and social interaction index $(\mathbf{F}$ and $\mathbf{I}) . \mathrm{N}=9$ mice for control, $\mathrm{n}=10$ for NEX-DSCAM f/f mice. Data were shown as mean \pm SEM. Ns, $p>0.05 ;{ }^{*} p<0.05 ; * \star p$ $<0.01$. Student's t-test for E, F, H, and I; One-way ANOVA for NEX-DSCAM f/f group in D and control group in G; Kruskal-Wallis test for control group in D and 
1321 memory in Barnes maze. Quantitative analysis of escape latency (J) and error

1322 numbers (K) in 4-day training session. Quantitative analysis of moved distances (L),

1323 latency to target $(\mathbf{M})$, time in target $(\mathbf{N})$ and correct pokes $(\mathbf{O})$ in the test session. $\mathrm{N}=$

132413 for control mice, $\mathrm{n}=11$ for NEX-DSCAM f/f mice. Data were shown as mean \pm

1325 SEM. Ns, $p>0.05 ;{ }^{*} p<0.05 ;{ }^{* \star} p<0.01$. Two-way ANOVA for J-K; student's t-test for

1326 L, M and O; Mann-Whitney $U$ test for N. P Schematic illustration for DSCAM

1327 deficiency on spine maturation. 
Figure. 1
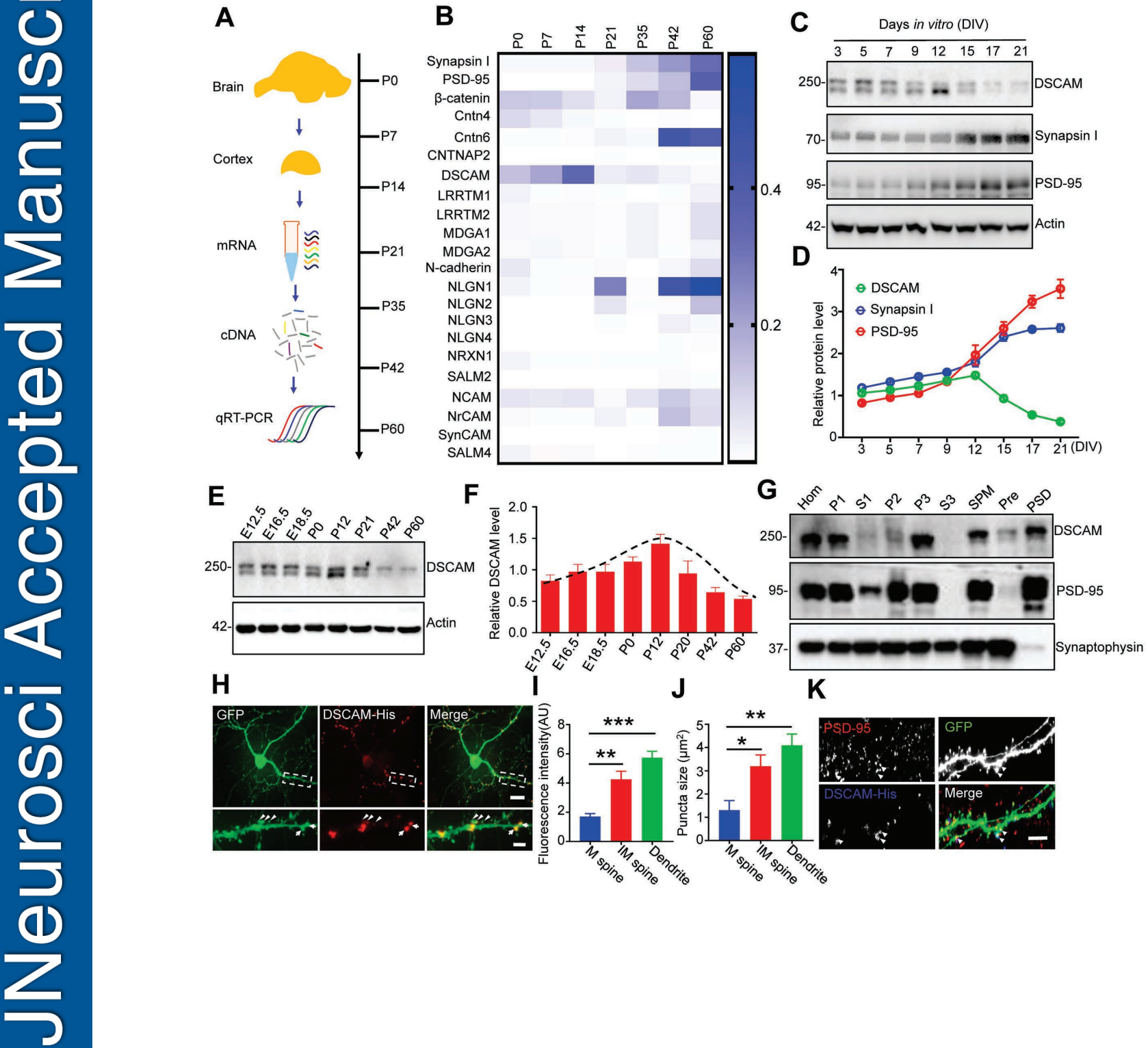
Figure. 2
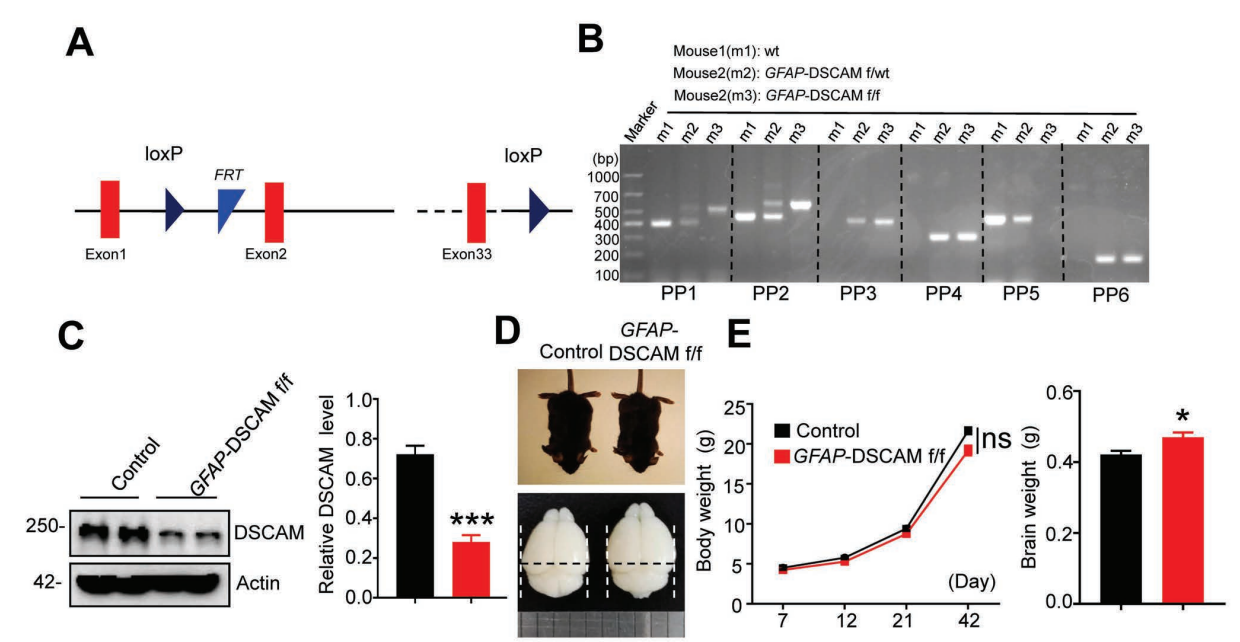

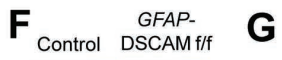
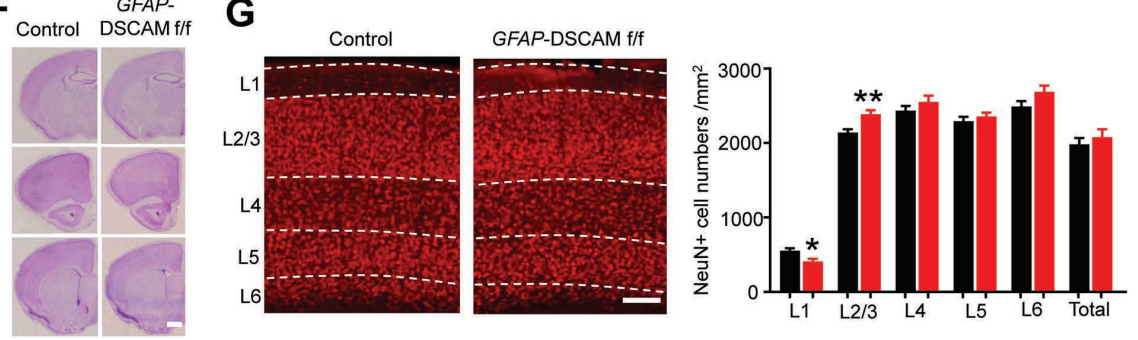

0
0
0
3
7
7
7
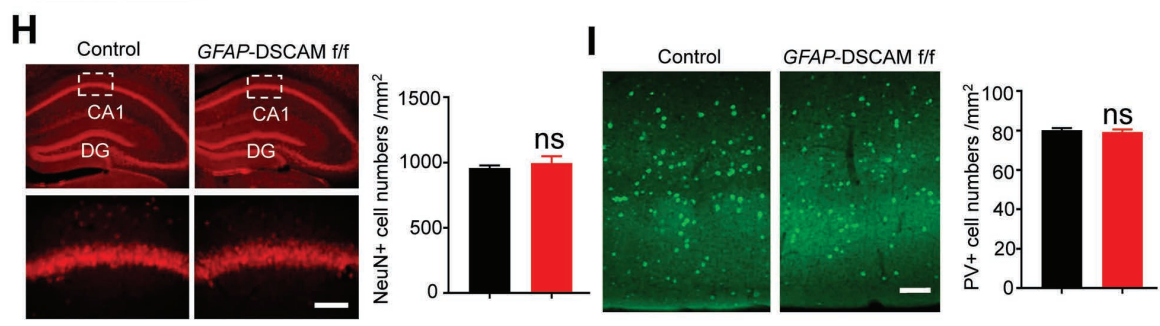
Figure. 3
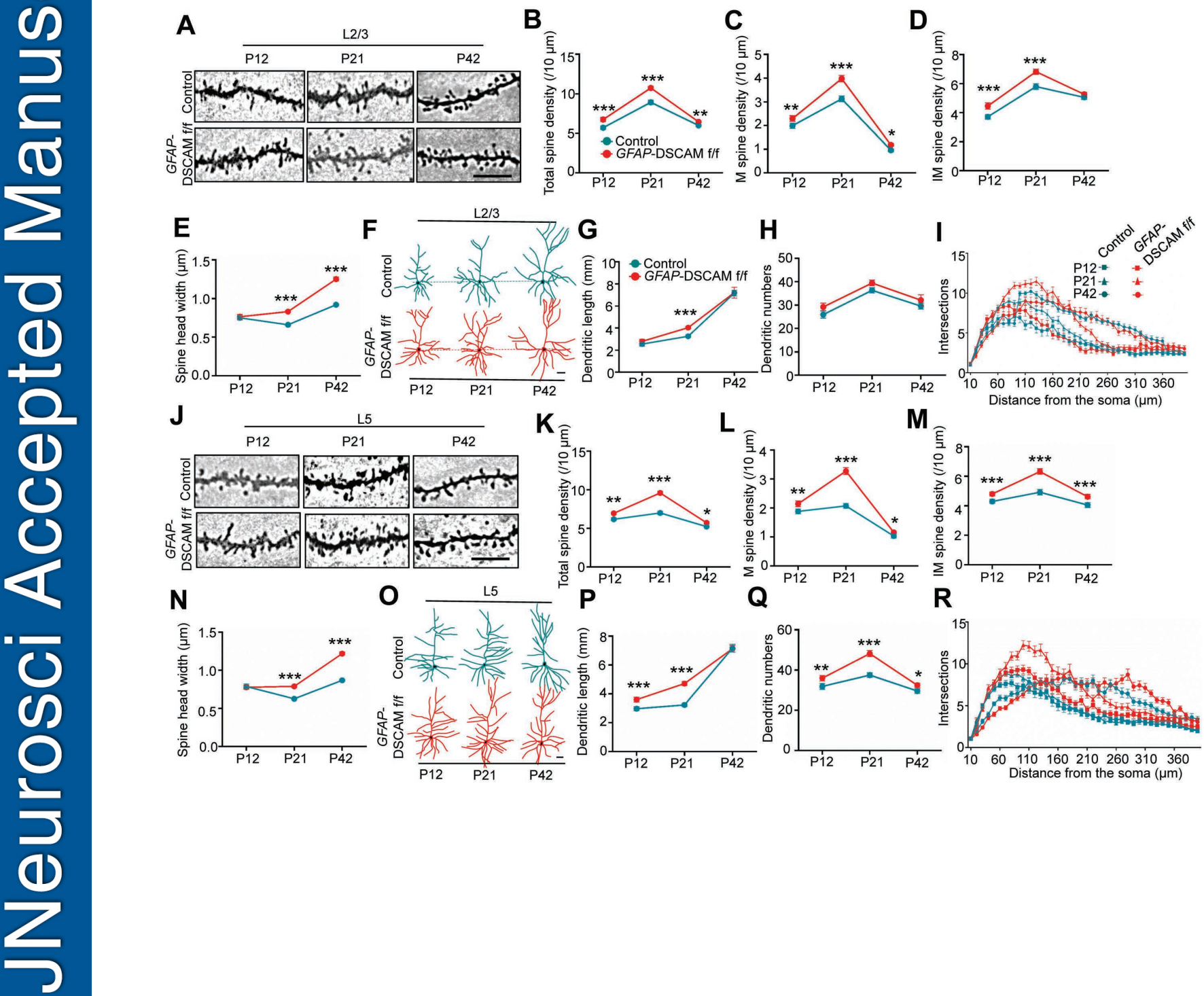
Figure. 4
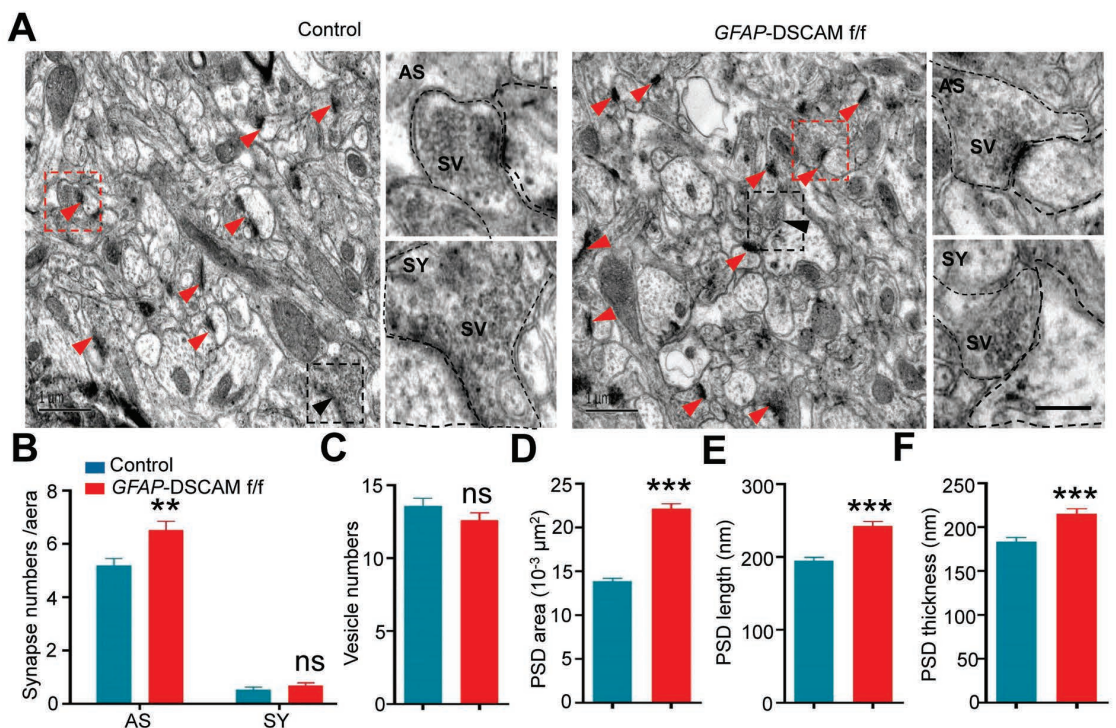
Figure. 5

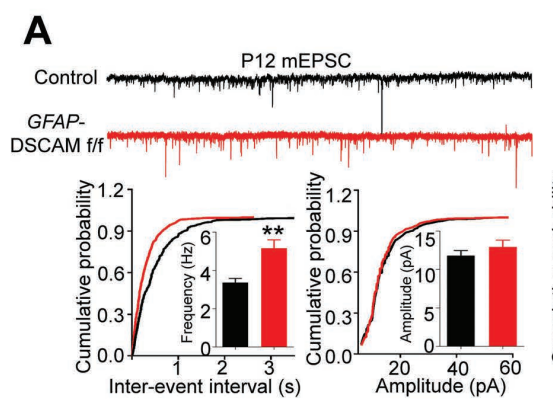

B

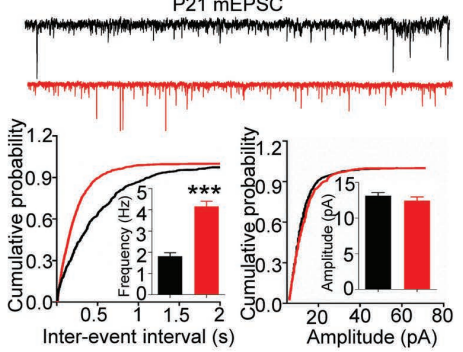

D

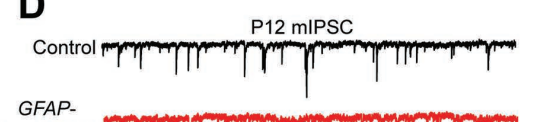

GFAP-
DSCAM If

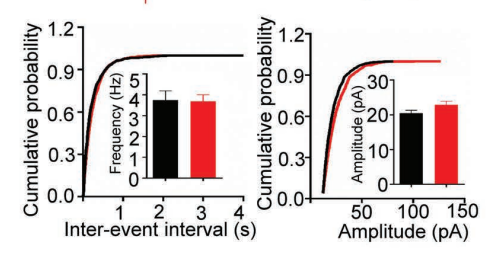

E

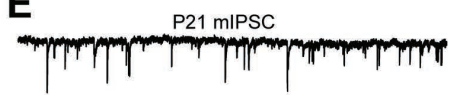

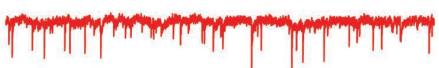

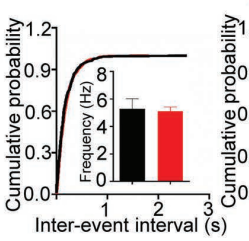

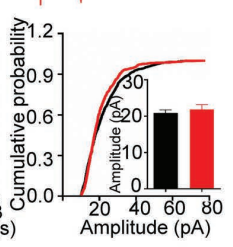

C
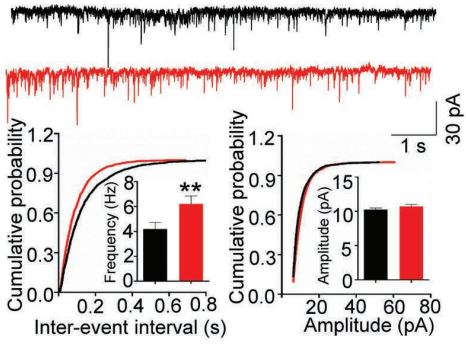

$F$

P42 mIPSC

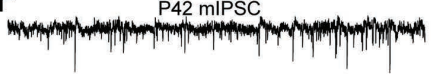

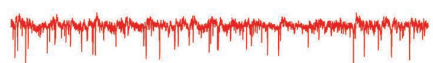

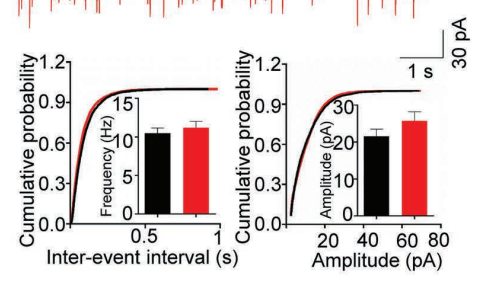


Figure. 6

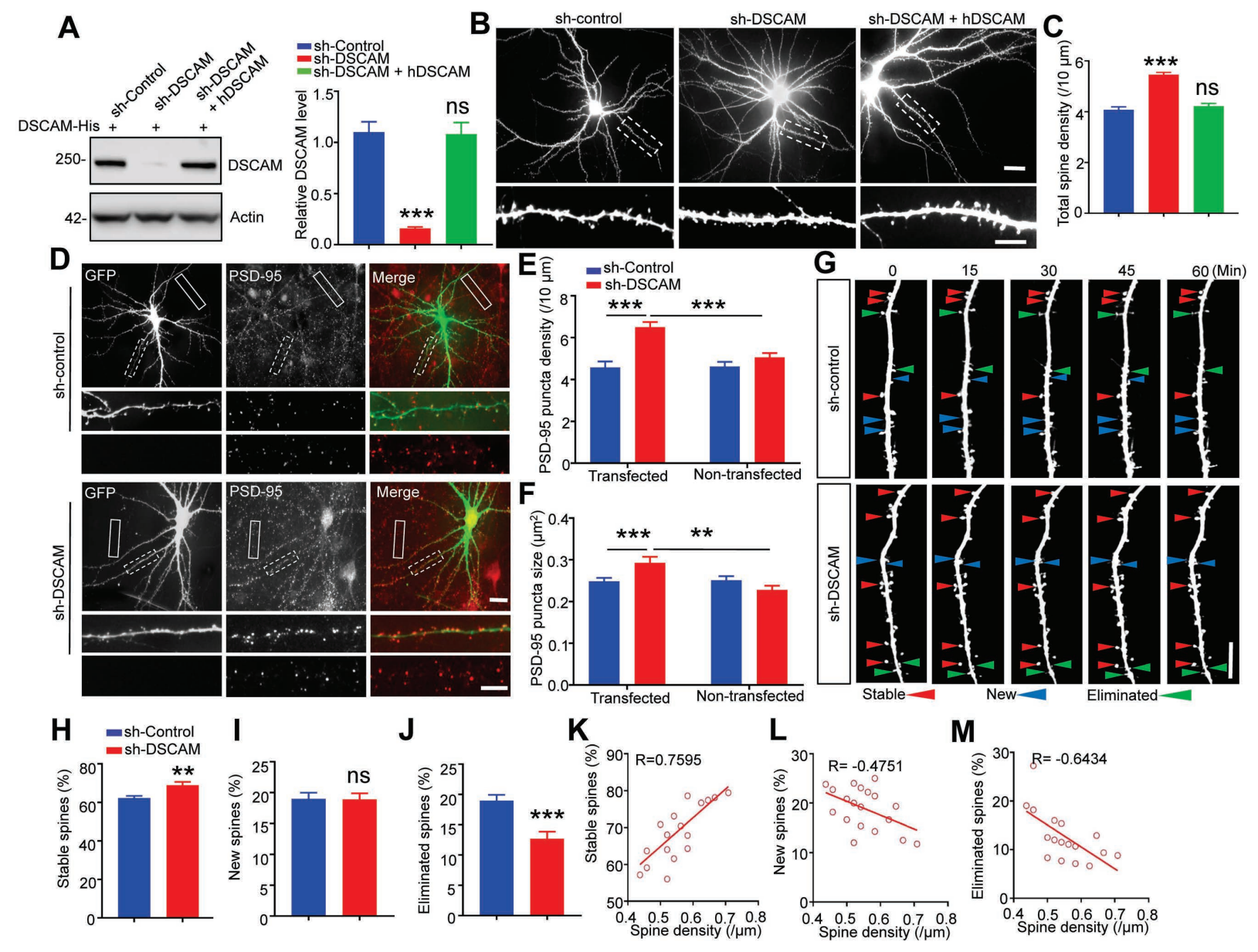


Figure. 7

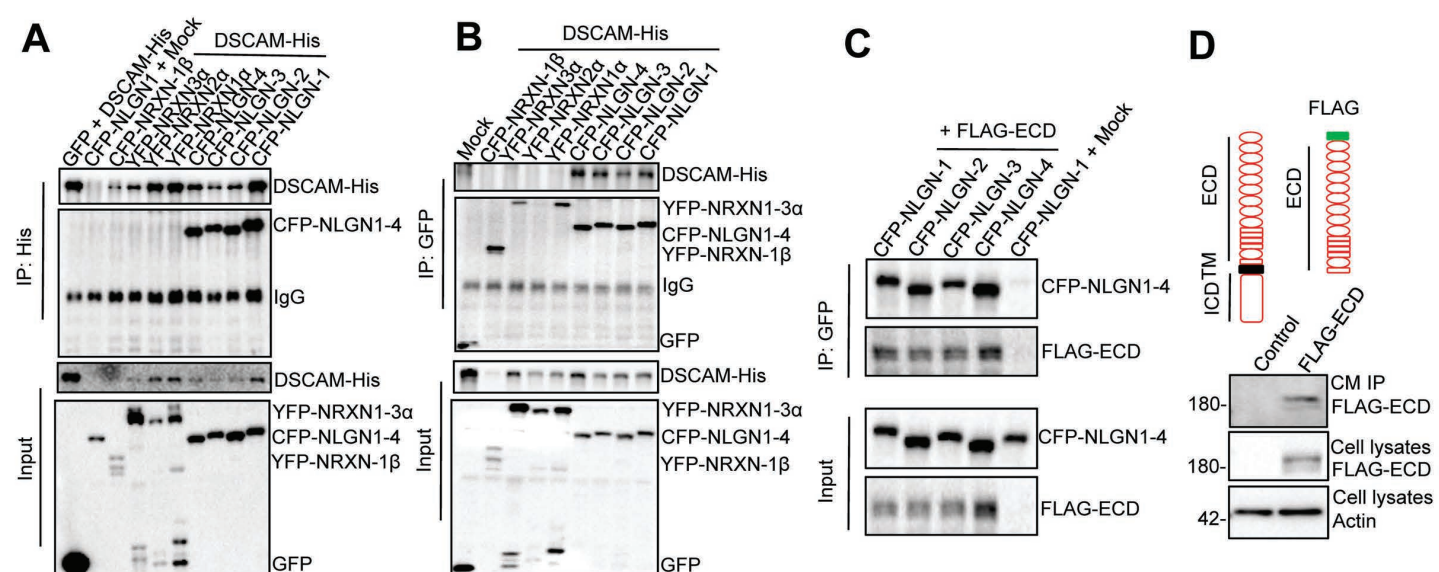

E
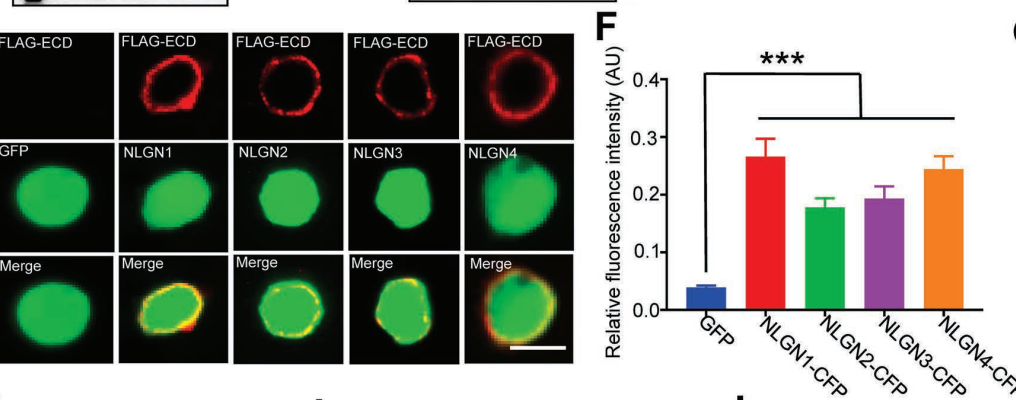

G
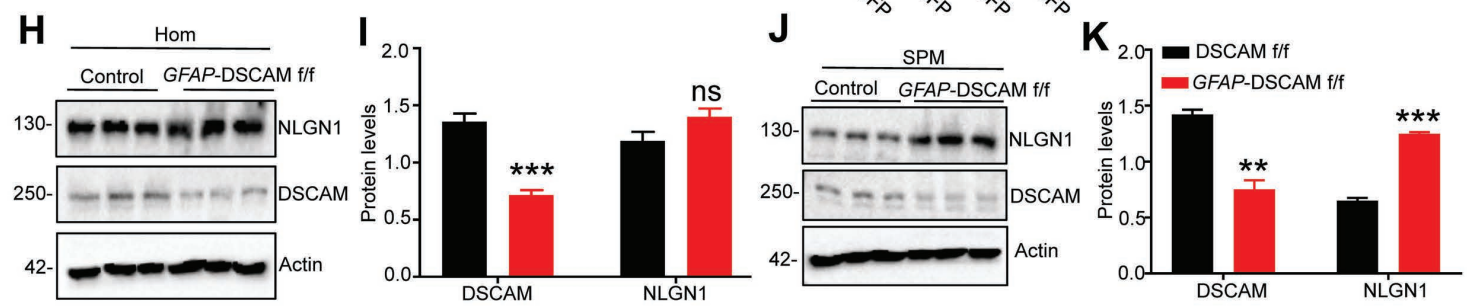
Figure.8

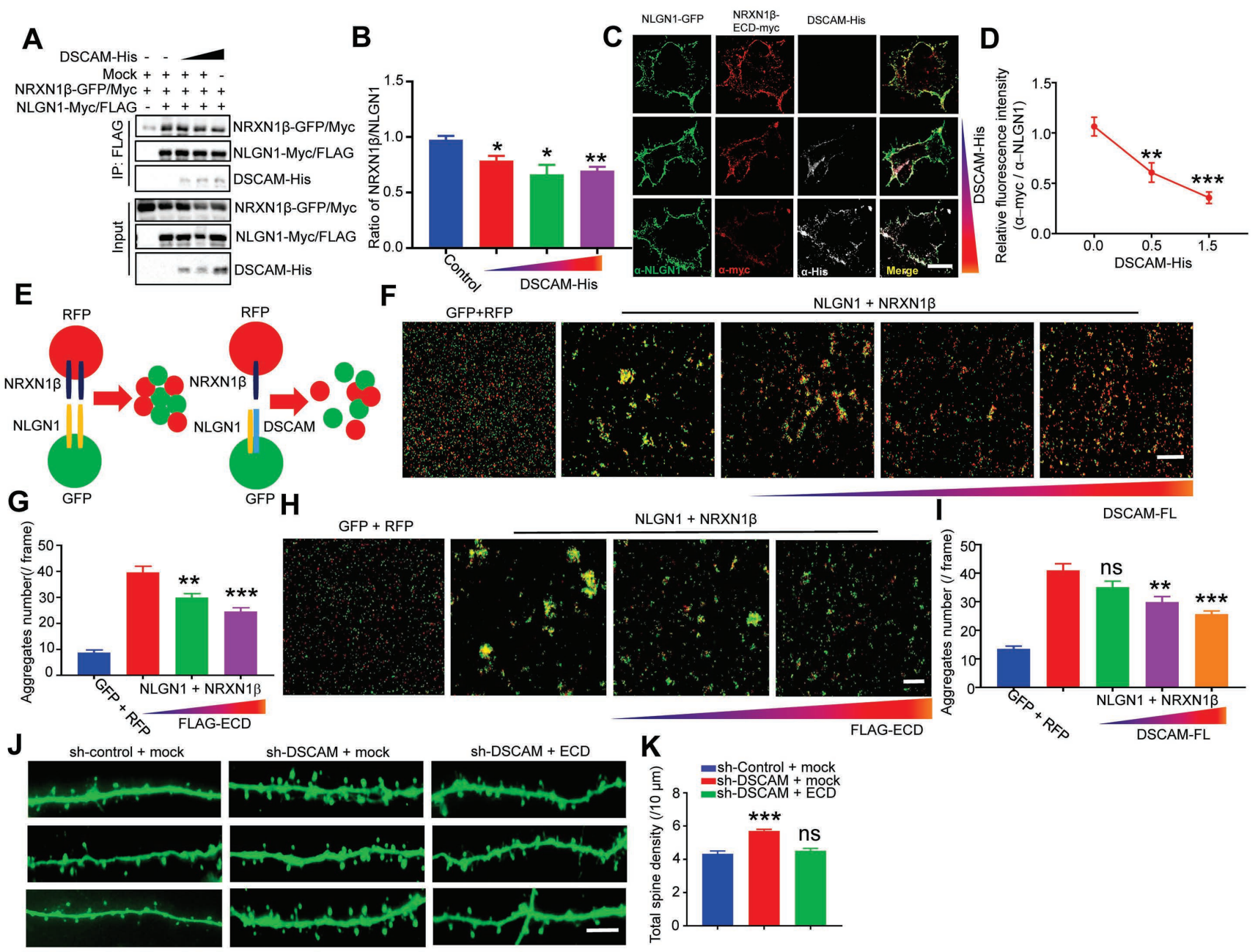


Figure. 9
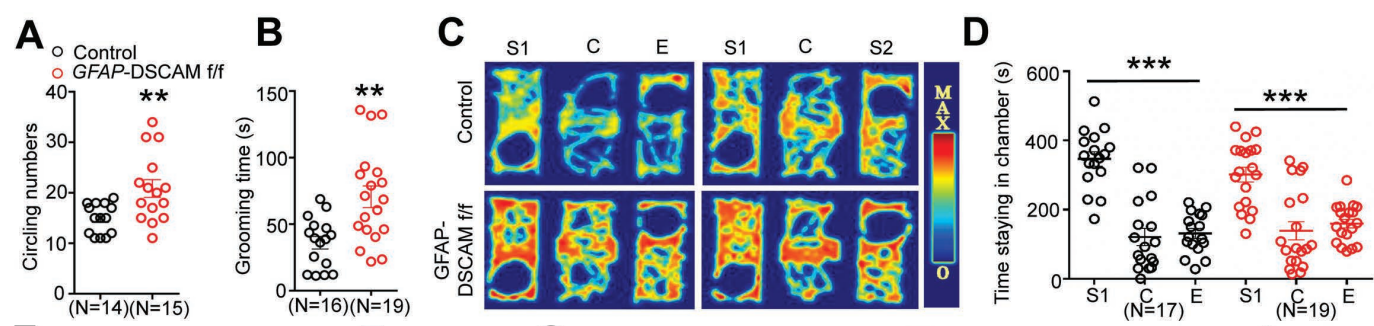

E

$\mathbf{F}$

$\mathrm{H}$

I

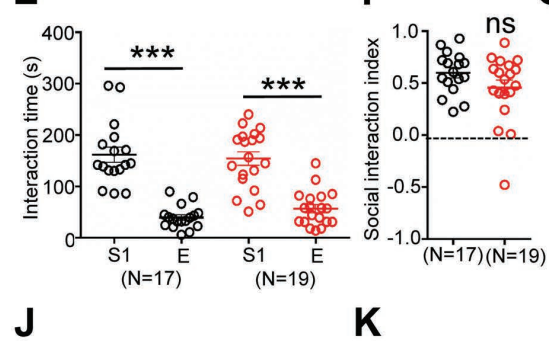

G

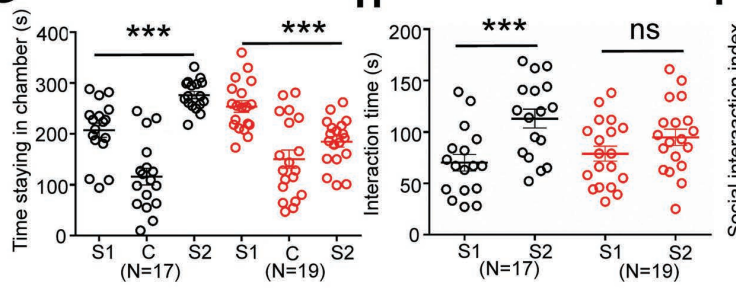

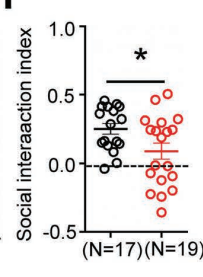
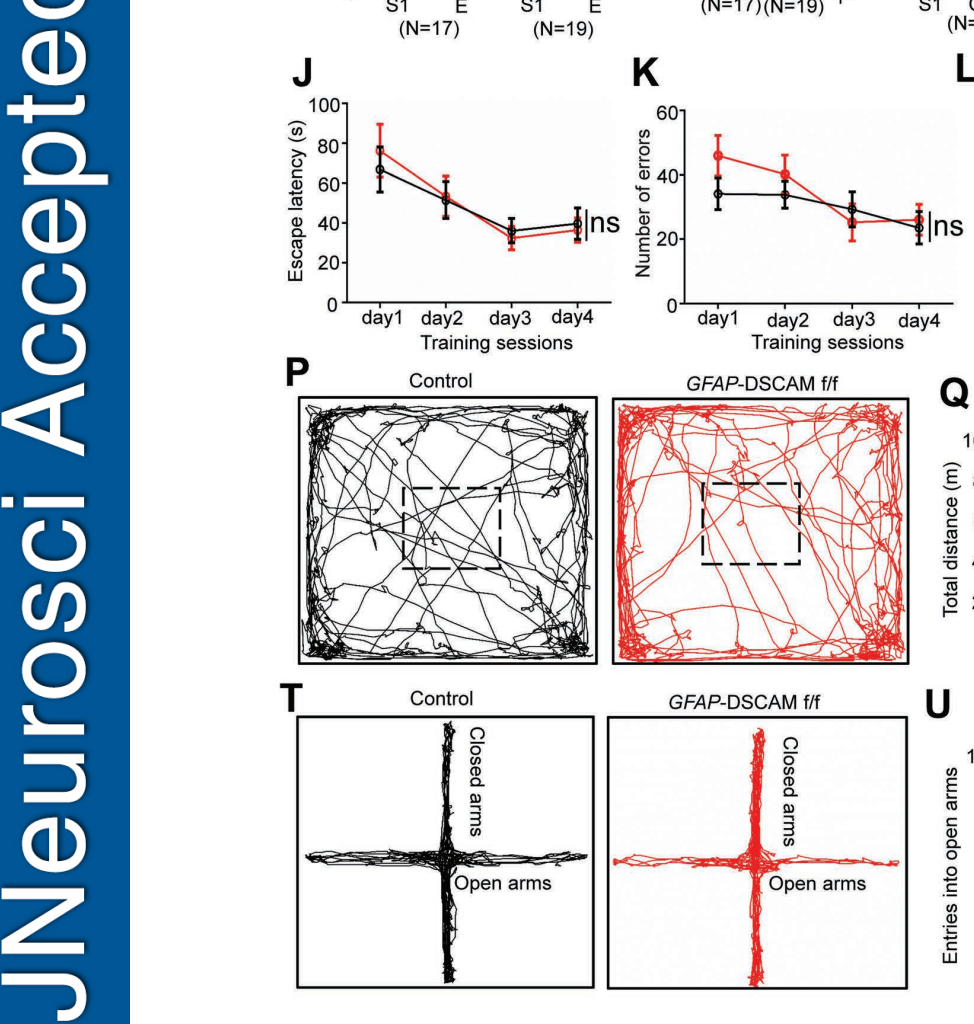

L M

N $\mathbf{O}$
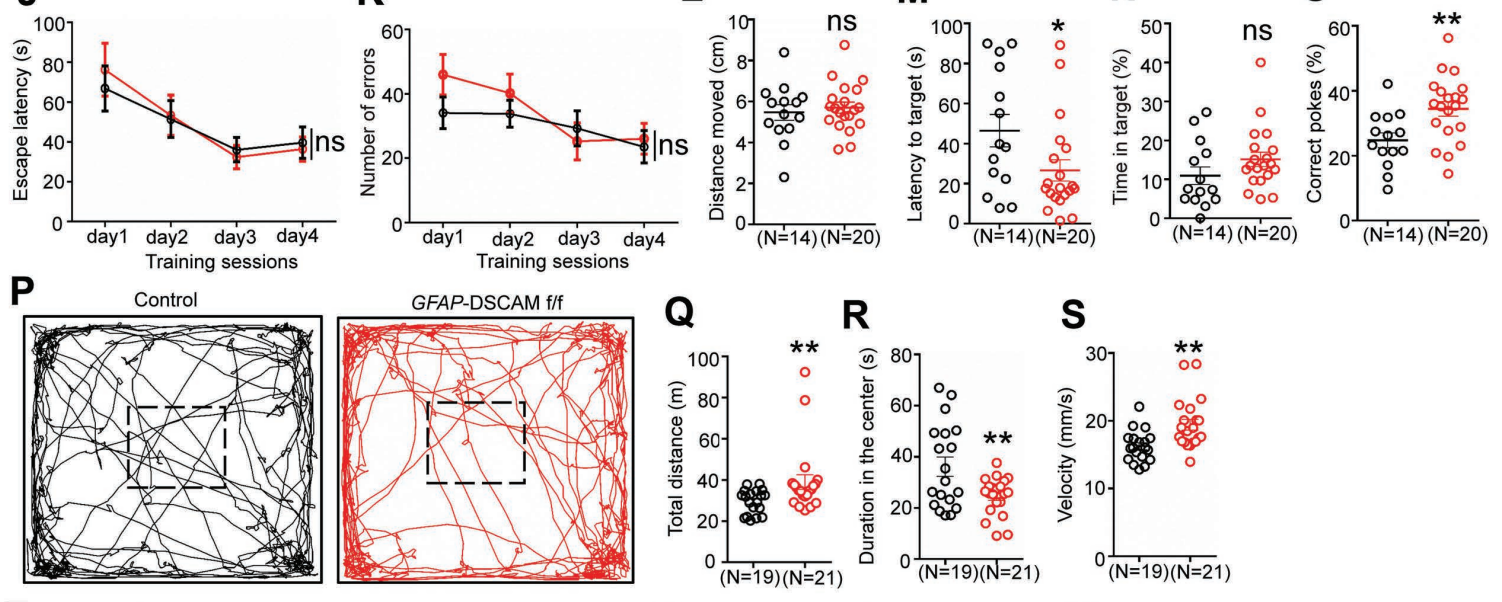

$\mathbf{R}$
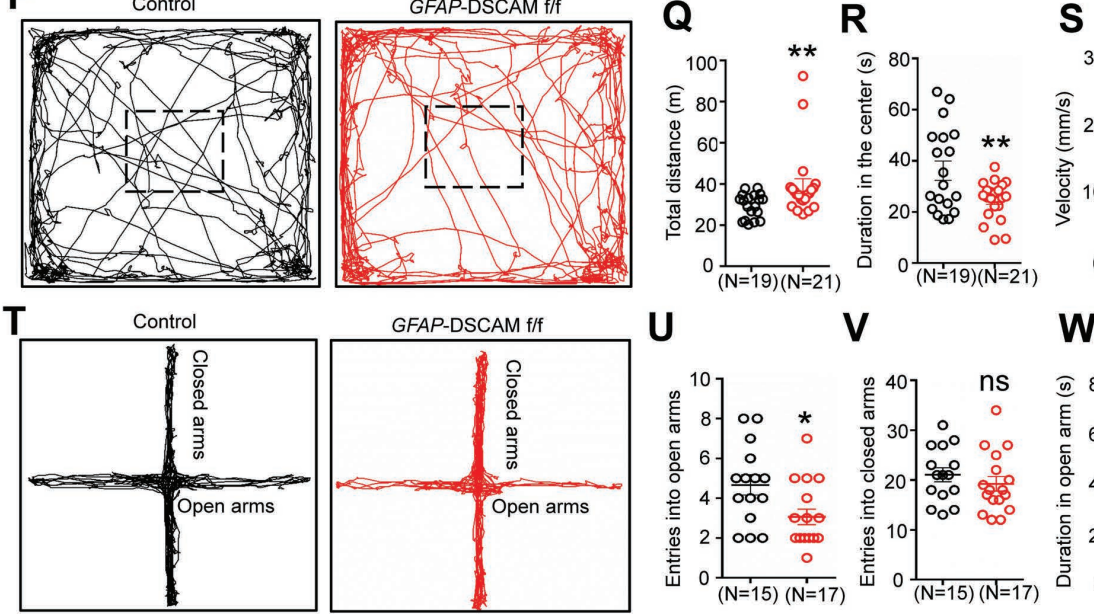

$\mathbf{U}$
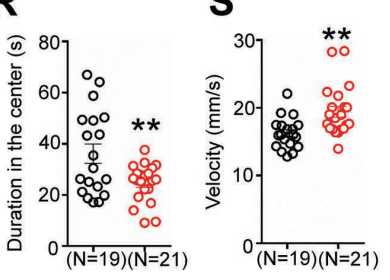

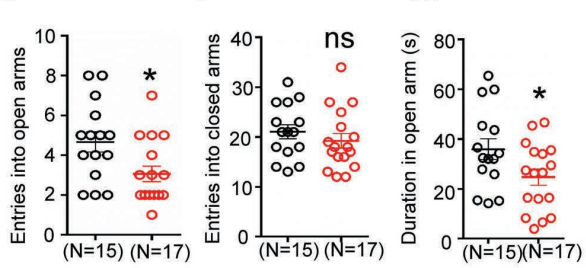


Figure. 10
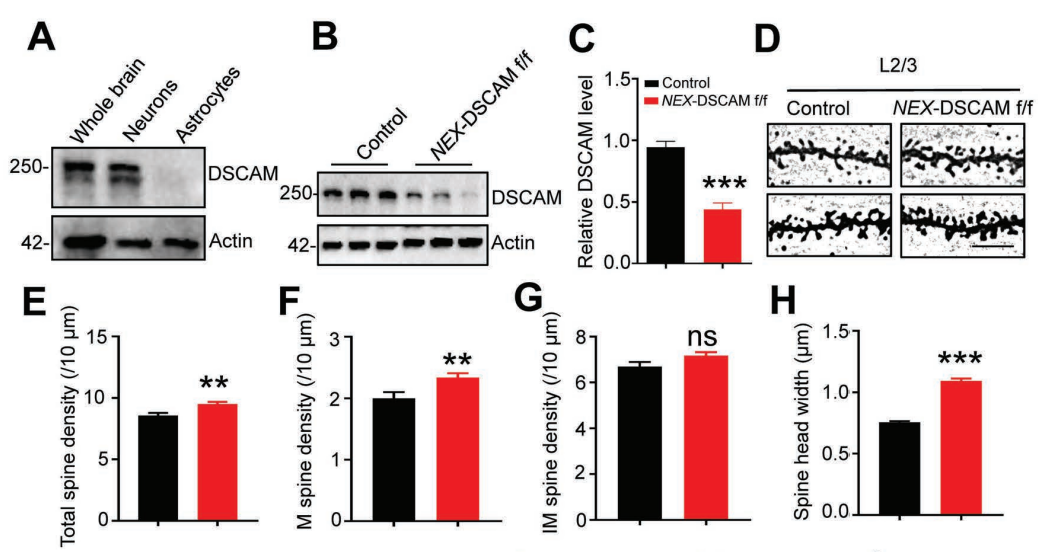

G
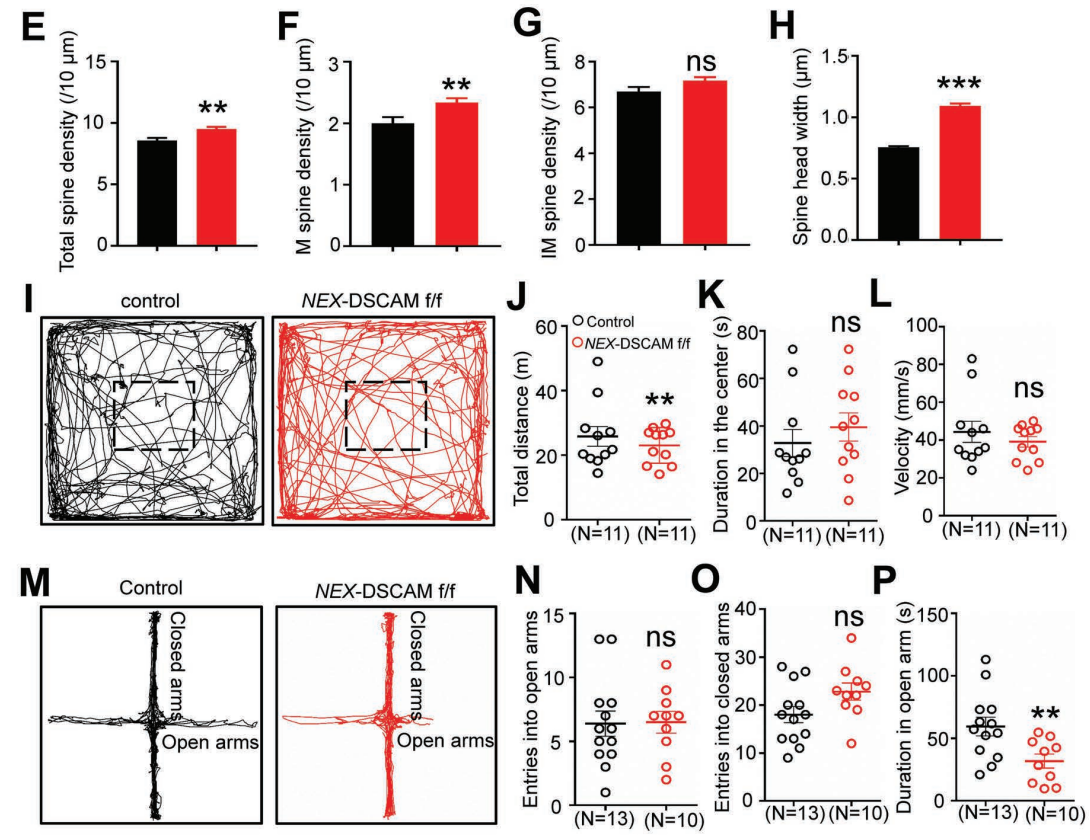
Figure 11
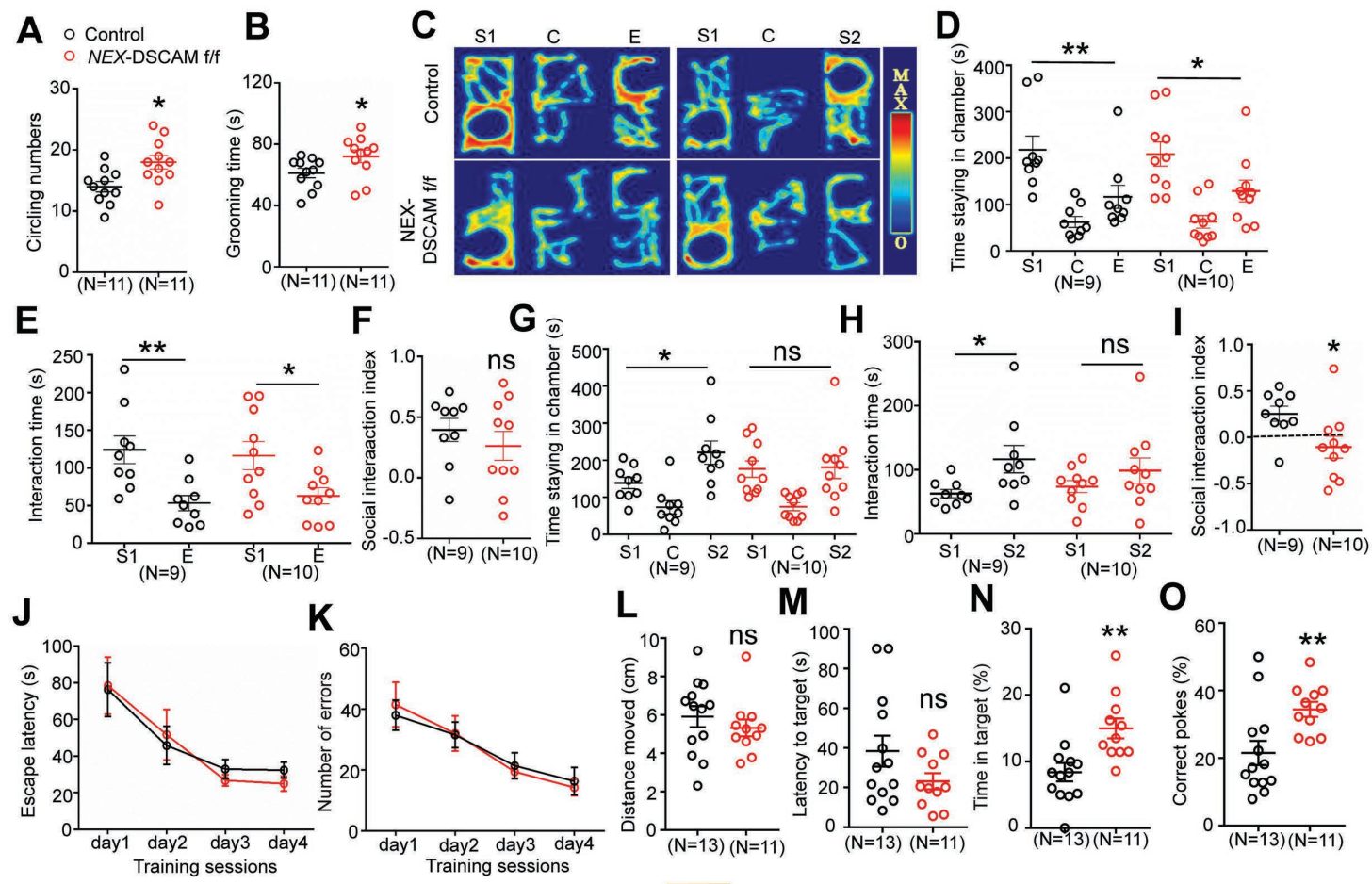

o

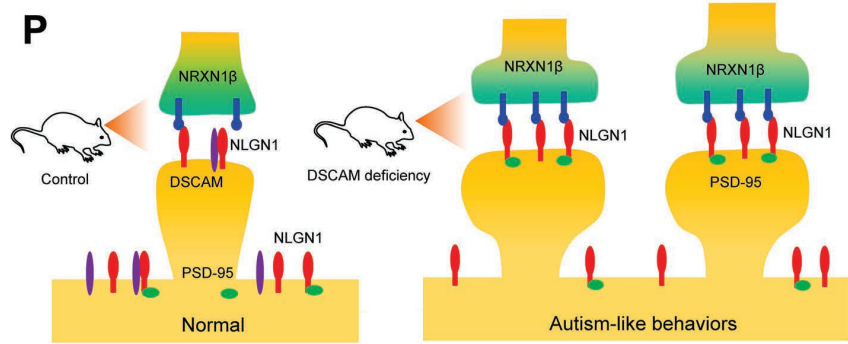

